\title{
POLÍTICA, DISCRECIONALIDAD Y DERECHO \\ EN LAS IMPLICACIONES EMPÍRICAS DEL PRINCIPIO DE PROPORCIONALIDAD DE LA PENA
}

Angelo Giraldi

E-mail: angelo.giraldi@um.es

\begin{abstract}
RESUMEN: El trabajo está encaminado a encuadrar jurídicamente las implicaciones empíricas del principio de proporcionalidad de la sanción penal. Para desarrollar un análisis que profundice tanto la predeterminación normativa de la proporcionalidad, como su aplicación en la fase del juicio y en la fase de ejecución de la pena, se analizarán varios aspectos relacionados con la política, la discrecionalidad y el Derecho Penal.

Palabras clave: Derecho Penal; pena; ponderación; proporcionalidad; sanción.

ABSTRACT: The paper aims at analyzing the practical aspects of the principle of proportionality of criminal sanctions. In order to develop an analysis that concerns the legislative predetermination of the sanction, and its application during trial and during the execution of the sanction, different aspects will be discussed. These aspects concern politics, discretion and Criminal Law.
\end{abstract}

Keywords: Criminal Law; justice; ponderation; proportionality; sanction.

\begin{abstract}
Sumario: I. Consideraciones introductivas. II. LA (PRE)DEterminaCión Normativa de la PENA. 2.1. Límites aplicativos del principio de proporcionalidad en abstracto. 2.2. La función del principio de proporcionalidad entre exigencias democráticas y discrecionalidad política. 2.3. Las posibles técnicas de normación a garantía del principio de proporcionalidad de la pena. III. LA DETERMinación JUDICIAL DE LA PENA. 3.1. La imposición de la pena como límite a la discrecionalidad penal. 3.2. El impracticable balance entre proporcionalidad en concreto y discrecionalidad del juez: posibles soluciones. IV. LA POST-DETERMiNACIÓN DE LA PENA EN LA FASE DE EJECUCIón. 4.1. La actuación del principio de proporcionalidad en la post-determinación de la pena. 4.2. La restorative justice en el futuro de la punibilidad: reparación proporcionada del daño.
\end{abstract}

\section{CONSIDERACIONES INTRODUCTIVAS}

Resulta complicado facilitar una explicación fenomenológica al instituto de la proporcionalidad de la pena. Como prueba de eso, no hay más que pensar en la dificultad de formular una completa definición de su significado. Parece casi imprescindible, al menos 
prima facie, proporcionar el concepto sobre la base de un ejemplo concreto. Se conocen, en tal sentido, las expresiones «Die Polizei soll nicht mit Kanonen auf Spatzen schießen» ${ }^{1}$ $\mathrm{y}$ «you must not use a steam hammer to crack a nut if a nutcracker would do» ${ }^{2}$. De no ser así, prescindiendo de cualquier escenario ejemplificativo, se correría el riesgo de no facilitar una definición pura y completa ${ }^{3}$.

En un primer momento, sobre todo cronológicamente, la aplicación del principio de proporcionalidad ha de insertarse en la actividad del órgano legislativo. El principio, de hecho, representa un corolario de exigencias que deben acompañar las sanciones penales, establecidas -en primer lugar- por el legislador. Este último, pues, elabora los textos normativos, que comprenden medidas sancionadoras que deberían con suerte reflejar los principios postulados por el derecho penal con arreglo a la Constitución, incluida la proporcionalidad de la pena.

Con frecuencia se habla de predeterminación normativa de la pena con respecto a la decisión del legislador de aparejar una u otra sanción a la comisión de una determinada conducta típica. Hay que subrayar que el significado atribuido a la expresión puede sufrir distorsiones, de las cuales conviene huir. El prefijo «pre» puede implicar la inferencia de dos diversas acepciones, que merece la pena distinguir ya que -si se utilizan alternativamente- pueden generar confusión también en relación con el tema que se analiza en los párrafos siguientes. Conviene mencionar que este prefijo oculta la polisemia del vocablo determinación, con respecto a la pena. Esta última, pues, es establecida ante todo por el legislador a nivel general y abstracto, luego es decidida concretamente por el hermeneuta, que efectúa otra determinación, relevante a los efectos prácticos. El recurso del reo ante la justicia, de hecho, estará encaminado a combatir esencialmente la pena impuesta por el órgano jurisdiccional, no la establecida a priori por el legislador ${ }^{4}$.

En primer lugar, pre-determinar una pena puede indicar la anterioridad cronológica de la actividad legislativa hacia la actuación judicial. Establece la pena, de hecho, ante todo el legislador, y sólo después la aplica el juez. En este sentido, se le confiere al vocablo «predeterminación» un significado meramente temporal.

Una segunda y diferente nuance de dicha palabra permite la atribución de una connotación que implica una evaluación cualitativa. Con esta acepción podría entenderse la predeterminación normativa como un paso subordinado a la verdadera determinación, es decir, la determinación judicial. Según dicha impostación, la determinación hermenéutica

1 «La policía no debe disparar a los gorriones con los cañones». Así FLEINER F., Institutionen des Deutschen Verwaltungsrechts, Tübingen, J.C.B. Mohr, 1911, p. 354.

2 «No tienes que usar un martillo de vapor para cascar una nuez cuando un cascanueces haría lo mismo». La expresión es indicada por AJANI G. - PASA B., Diritto comparato. Casi e materiali, Turín, Giappichelli, 2013, p. 71.

3 A nivel semántico, la proporcionalidad es definida como metáfora y por eso es «misión ilusoria» intentar darle una definición sintética, «porque si parece simple entenderla, no es nada simple la acción de los dispositivos mentales que permiten su producción e interpretación». Así GARAVELLI B.M., Manuale di retorica, Milán, Bompiani, 2003, p. 160. La metáfora, de hecho, según la enseñanza de ECO U., Semiotica e filosofia del linguaggio, Turín, Einaudi, 1984, p. 141, «reta cada voz enciclopédica».

4 No se pretende afirmar, con estas palabras, que el (posible) reo no pueda acudir la jurisdicción estatal para denunciar la irregularidad de una previsión normativa. Queda siempre, pues, la posibilidad de recurrir para denunciar, por ejemplo, vicios de incostitucionalidad de las sanciones por la falta de respeto de los preceptos constitucionales. Sin embargo, la concreta utilidad que suele buscar el sujeto con el recurso ante los órganos jurisdiccionales no se encuentra en la revisión de una disposición general y abstracta, sino más bien en la nueva determinación de la aplicación de la norma en el caso específico. 
de la pena, precedida por un iter normativo formalmente regular, jugaría un papel primario en la lógica de conminación de la sanción. La pre-determinación legislativa sería, pues, un paso lógico inferior a la efectiva irrogación decidida por el juez.

Pre-determinar una pena a nivel normativo puede indicar, pues, tanto la anterioridad cronológica de la actividad legislativa como su posterioridad ontológica; en este último sentido, la predeterminación consistiría en un paso obligado y anterior, pero no vinculante, respecto al proceso decisorio judicial. A fin de evitar instrumentalizaciones impropias de la semántica jurídica, resulta significativo subrayar que la primera de las dos acepciones mencionadas es sin duda correcta, mientras que la segunda no cumple los requisitos del Estado de Derecho. En la estructura actual del ordenamiento jurídico, de hecho, es la ley la que prima sobre el poder estatal, y entonces sobre la jurisdicción y su actuación. Los jueces, en efecto, no son sino la boca de la ley ${ }^{5}$. Cuando se habla, pues, de predeterminación normativa de la pena, se indica su anterioridad cronológica respecto a la determinación judicial, y también la ontológica pero sólo desde el punto de vista sistemático. En este sentido, por su misma naturaleza, es el juez el que debe tomar en consideración y aplicar el precepto normativo establecido por el legislador; no cabe lo contrario.

A lo mejor conviene eliminar el prefijo y distinguir únicamente a través del adjetivo las dos fases que caracterizan la introducción de la pena en el sistema normativo: determinación normativa y determinación judicial, a las cuales se añadirá una tercera fase relativa a la aplicación de la sanción. Estos son los tres estadios en los cuales se inscribirá el análisis empírico del principio de proporcionalidad.

\section{LA (PRE)DETERMINACIÓN NORMATIVA DE LA PENA}

La aplicación del principio de proporcionalidad a nivel general y abstracto por parte del legislador representa una actividad difícil para el operador jurídico, ya que su carácter empírico no beneficia a una reconstrucción objetiva de su estructura. De hecho, razonar en términos abstractos acerca de un principio que favorece una actuación distinta caso por caso es sin duda un esfuerzo apriorístico que de por sí no garantiza el respeto de la proporcionalidad. Cabe mencionar que en doctrina hay manifestaciones acerca de la posibilidad de enmarcar a nivel lógico y coherente el principio en cuestión ${ }^{6}$. Algunas corrientes doctrinales, de hecho, enmarcan el derecho en un contexto perfecto y cristalino que huye de cualquier falta de lógica o coherencia. Aun así, en contra de los que afirman la exhaustividad y la coherencia del ordenamiento, basta con pensar en los instrumentos que

5 La célebre expresión del filósofo francés Montesquieu indica que la jurisdicción sólo es la bouche de la loi. Los jueces, de hecho, actúan en el derecho únicamente en calidad de intérpretes y, de ser así, desde luego no pueden modificar, ni distorsionar, la voluntad legislativa, establecida directamente por el poder constitucionalmente determinado. Se trata de un notorio principio que deriva de la Ilustración y ha sido positivizado como fuente primaria en la Constitución, que expresa con firmeza el sometimiento, único y exclusivo, del poder jurisdiccional a la ley. Para explorar el vasto tema de las relaciones entre poder legislativo y judicial con respecto al derecho penal, v. MILONE S., «Legalità e ruolo creativo della giurisprudenza nei rapporti tra diritto penale e processo», www.penalecontemporaneo.it, 10 de octubre de 2016. La autora cuestiona la función del «derecho de los jueces» en el sistema de las fuentes, teniendo siempre en consideración la compatibilidad del mismo con la garantía de la legalidad penal, en su significado propio de la Constitución y de la Convenio Europeo de Derechos Humanos de 1950.

6 En favor de la lógica y coherencia del derecho se expresa ALEXY R., «La formula per la quantificazione del peso del bilanciamento», Ars interpretandi, 2005, p. 97 y ss. Vid., amplius, ALEXY R., Teoria dei diritti fondamentali, Bolonia, Il Mulino, 2012, passim. 
las mismas normas prevén para integrar lagunas o antinomias, los cuales, si por un lado están encaminados a eliminar irracionalidad y contradicciones, por otro son insuficientes para colmar las deficiencias del derecho, demostrando su carácter puramente imperfecto y caracterizado por constante mutabilidad.

El análisis jurídico del principio de proporcionalidad, ya que no puede utilizar instrumentos derivantes de la lógica cristalina del derecho, impulsa a emplear un argumento que sea lo más racional posible ${ }^{7}$. Eso, habida cuenta de las dificultades del razonamiento en abstracto, permite el debate y testifica la viabilidad de dicho estudio ${ }^{8}$.

La proporcionalidad en abstracto, en definitiva, está relacionada con la conexión entre delito y pena así como previsto por el legislador. Se diferencia desde esta perspectiva de la proporcionalidad a nivel concreto, que se refiere, en cambio, a la relación entre el hecho histórico delictivo y la gravedad de la pena efectivamente impuesta al delincuente. En abstracto, el principio de proporcionalidad puede considerarse a nivel objetivo, subjetivo, absoluto o relativo: (a) en primer lugar, la proporción objetiva toma en consideración la correspondencia entre la pena y el desvalor de la violación de la norma jurídica, calculado con arreglo al perjuicio sufrido por el bien jurídico tutelado. En otras palabras, el principio en sentido puramente objetivo se manifiesta en la antigua lex talionis, baluarte del derecho primitivo. La violación de un precepto jurídico, pues, implica la aplicación de una sanción sobre la base de una equivalencia cuantitativa entre dos grandezas cualitativamente heterogéneas: la aflictividad de la pena y el daño social del delito9; (b) a nivel subjetivo, por el contrario, la determinación de la pena tiene en consideración la intensidad de la culpabilidad y el grado de participación personal de la voluntad del reo, tal y como se ha manifestado en la conducta típica ${ }^{10}$; (c) desde una perspectiva más amplia, es posible considerar la proporcionalidad de la pena de manera absoluta, lo que permite el examen de la sanción por sí misma, tanto a nivel objetivo como subjetivo, sin tomar en consideración otras species del mismo genus para efectuar una operación comparativa; (d) si el examen está encaminado a comparar dos sanciones y, sobre la base del resultado, analizar su proporcionalidad, se considera el principio de manera relativa.

El principio de proporcionalidad a nivel abstracto se afirma como un límite de las decisiones legislativas desde un doble punto de vista ${ }^{11}$. Ante todo, ese principio vincula al

7 Conviene mencionar la distinción entre dos conceptos que a menudo se confunden con respecto a su significado, es decir, racionalidad y razonabilidad. «Racional» indica la coherencia lógica de un sistema, «razonable» su adecuación a un valor, como expresa PAGLIARO A., Il diritto penale fra norma e società. Scritti 1956-2008, vol. III, Milán, Giuffrè, 2009, p. 1042. El autor propone algunos ejemplos en materia de pena. Piénsese en la disciplina de la detención ilegal: si la pena fuese menos grave en el caso de que la víctima muera o si las víctimas sean dos o más, es claro que el Tribunal Constitucional podría afirmar que no se trata de discrecionalidad legislativa, sino de mera arbitrariedad ilógica. Otro ejemplo concreto, propuesto por el autor, es el de la ley que establezca que el nivel de la sanción por un determinado delito se hallase influenzado por suerte o mediante prácticas de magia.

8 En este sentido se expresa MERLO A., «Considerazioni sul principio di proporzionalità nella giurisprudenza costituzionale in materia penale», Rivista italiana di diritto e procedura penale, 2016, $\S 8$.

9 PALAZZO F., Corso di diritto penale. Parte generale, Turín, Giappichelli, 2016, p. 30.

10 Para ser conforme al principio de proporcionalidad, la pena ha de resultar psicológicamente proporcionada al delito. Así MANZINI V., Trattato di diritto penale italiano, vol. III, Turín, Utet, 1986, p. 4.

11 Los dos puntos de vista se encuentran en MANES V., «I recenti tracciati della giurisprudenza costituzionale in materia di offensività e ragionevolezza», www.penalecontemporaneo.it, 10 de octubre de 2011, p. 2, en relación con una sentencia del Tribunal Constitucional italiano en que el principio de proporcionalidad juega un papel primario, afirmándose como orientación limitativa de las decisiones legislativas también con respecto al quantum de la sanción y a las vinculaciones puestas a la discrecionalidad judicial. 
órgano legislativo para que establezca un quantum determinado en la sanción. De hecho, la determinación normativa de la pena debería tender a la deferencia más compacta del principio de proporcionalidad. En segundo lugar, el principio permite al poder legislativo la constricción de la discrecionalidad judicial, restringiendo las conminaciones de esta última al marco edictal establecido a priori.

La legitimación democrática del derecho penal, en efecto, no puede prescindir de la garantía -al menos en la perspectiva teórica- de racionalidad y ponderación ${ }^{12}$ a la hora de efectuar el balance entre respectivos costes y beneficios ${ }^{13}$. A efectos de garantizar dicha racionalidad, es necesario que la pena se evalúe con arreglo al cumplimiento de algunos requisitos específicos ${ }^{14}$ : (i) en primer lugar, hay que considerar el balance entre el bien jurídico principal, tutelado por la norma jurídica, y los demás intereses que rodean la esfera aplicativa de la norma penal; (ii) el segundo canon a examinar, luego, es la proporción entre costes y beneficios de tutela, es decir que se necesita una evaluación general de los efectos positivos y negativos generados por la incriminación; (iii) en tercer lugar, es oportuno que el medio con que se quiere alcanzar el objetivo a tutelar sea adecuado a este último ${ }^{15}$; (iv) por último, el interés tutelado por la norma sancionadora debe merecer intrínsecamente la tutela penal, con arreglo a las indicaciones constitucionales, desde luego inderogables.

El criterio de proporcionalidad, entendido como balance entre los bienes jurídicos que se disputan la primacía en la dialéctica delito-sanción, puede ser representado idealmente como una curva de indiferencia entre cantidades de protección diferentes de dos bienes ${ }^{16}$. Esta curva, de hecho, tiende a no comprimir los bienes en cuestión, evitando así que se llegue a la aniquilación de uno en favor del otro. Ambos los bienes jurídicos, pues, deben continuar a vivir por encima de un nivel mínimo necesario para remover la eventualidad de que los derechos del individuo sean anulados.

Es interesante señalar, con respecto a los intereses jurídicos en juego, que la relevancia del bien a proteger es fuente de legitimación de la intervención sancionadora en materia penal. De hecho, sobre la base de la importancia que reviste cada interés que se analice en un caso específico, el derecho penal puede actuar de manera más o menos incisiva a nivel sancionador ${ }^{17}$. Sobre la misma base, puede además anticiparse la tutela penal,

12 FIANDACA G., «Legalità penale e democrazia», Quaderni fiorentini, 2007, p. 1251.

13 Como se ha dicho anteriormente, el principio de proporción expresa una lógica costes-beneficios, más precisamente consagra la exigencia de que las ventajas para la sociedad derivantes de la conminación de una pena sean comparadas con los costes inherentes a la previsión de aquella pena: costes sociales (también económicos) e individuales, en términos de sacrificio para los bienes de la libertad personal, del patrimonio, del honor. Así se expresan MARINUCCI G. - DOLCINI E., Manuale di diritto penale. Parte generale, Milán, Giuffrè, 2012, pp. 11-12.

14 Los canones de racionalidad político-criminal son fruto de una síntesis de la jurisprudencia constitucional italiana, efectuada por RIONDATO S., Un diritto penale detto «ragionevole». Raccontando Giuseppe Bettiol, Padua, Cedam, 2005, pp. 129-130. Sub notas 442 y ss. consta una amplia literatura jurisprudencial que testifica el utilizo de tales canones para la evaluación de las normas penales con arreglo a la proporción.

15 A este respecto, «[t]his principle operates so as to place limitations on the amount of force that may properly be used in conditions of necessity. No individual, even an offender, should have his or her interests sacrificed except to the extent that it is both absolutely necessary and reasonably proportionate to the harm committed or threatened. This should apply equally to law enforcement officers and to ordinary citizens». ASHWORTH A., Principles of Criminal Law, Oxford, Oxford University Press, 2009, p. 57.

16 CERRI A., «Dalla garanzia del 'giusto procedimento' in sede disciplinare al criterio della 'proporzionalità': spunti problematici e riflessioni a partire da un'interessante sentenza della Corte», Giurisprudenza costituzionale, 1975, p. 1649.

17 Efectúa esta reflexión MANNA A., Corso di diritto penale. Parte generale, Padua, Cedam, 2015, pp. 29-30. El autor releva que el principio de proporción implica una tendencial legitimación de la intervención del derecho 
o sea es posible prever una pena no sólo para conductas típicas de daños, sino también para las de peligro. Desde esta perspectiva, se puede conminar una sanción por un hecho que, aunque no represente la verificación de un daño concreto, ponga en peligro un determinado bien jurídico. Cuanto más es elevado el rango del interés a proteger, en relación con el balance a efectuarse a efectos de proporcionalidad, más se permite la anticipación de la garantía penal.

Por ejemplo, el delito de desastre previsto en el artículo 434 del Código Penal italiano ${ }^{18}$ regula dos hechos típicos, el primer de los cuales, descrito en el primer apartado, lleva aparejada la sanción de la reclusión de uno a cinco años por haber provocado un peligro $^{19}$ para la seguridad pública. Si el desastre se lleva a cabo, se configura un delito de daño, previsto en el segundo apartado con relativo endurecimiento de la pena. Con respecto al delito de peligro concreto establecido en el apartado primero, ése encuentra su justificación en la relevancia del bien jurídico subyacente. De hecho, la seguridad pública que la norma protege asume una importancia significativa dentro de la jerarquía de los bienes jurídicos. Por esta razón, en el marco del principio de proporcionalidad, el balance de los intereses en juego -la libertad del reo y su castigo por haber socavado la integridad pública - tiene en consideración el rango esencial de esta última y justifica así la anticipación de la tutela penal.

La evaluación cualitativa de los bienes jurídicos que compiten por la primacía una vez que están tipificados es el resultado de decisiones político-criminales efectuadas $a$ priori por parte del legislador. Dichas determinaciones apriorísticas deben necesariamente tener en cuenta, so pena de responsabilidad esencialmente política, el desvalor social ${ }^{20}$

penal. Cuanto más se eleva el rango del interés a proteger, más es relevante el valor del interés en cuestión, y más se permite la anticipación de la tutela penal. Según dicha opinión, la estructura de la proporcionalidad no puede prescindir de una relación entre el bien jurídico a proteger y el que inevitablemente ha de ser sacrificado, con arreglo a los caracteres del derecho penal de fragmentariedad y extrema ratio. De hecho, no parece justificada la privación de libertad personal y de los demás bienes en relación con la tutela de intereses de rango inferior. El autor reitera que el principio de proporcionalidad, sin embargo, no opera sólo en la elección de la técnica de tutela penal y en el grado de anticipación de ella, sino también en la elección de una sanción que sea, ya en abstracto, ponderada respecto a la entidad del delito cometido.

18 El art. 434 del Código Penal italiano, cuyo encabezamiento es «Colapso de construcciones u otros desastres dolosos», establece que el que cometiera un hecho encaminado a provocar el colapso de una construcción o de una parte de ella, u otro desastre, será castigado con la reclusión de uno a cinco años si de la conducta derivase un peligro para la seguridad pública. Si el colapso o desastre se realizara, la pena será de tres a doce años de reclusión.

19 Sobre la noción de peligro en la estructura del hecho delictivo, v. CEREZO MIR J., «Los delitos de peligro abstracto en el ámbito del Derecho penal del riesgo», Revista de derecho penal y criminología, 2002, pp. 4772; HERNÁNDEZ PLASENCIA J.U., «Delitos de peligro con verificación de resultado. ¿Concurso de leyes?», Estudios jurídicos: libro conmemorativo del bicentenario de la Universidad de la Laguna, 1993, pp. 403-430; BARBERO SANTOS M., "Contribución al estudio de los delitos de peligro abstracto», Anuario de derecho penal $y$ ciencias penales, 1973, pp. 487-498; GALLO M., Diritto penale italiano. Appunti di parte generale, vol. I, Turín, Giappichelli, 2014, p. 235 y ss.; ROMANO B., Diritto penale. Parte generale, Milán, Giuffrè, 2016, p. 218 y ss.; sobre los delitos de peligro, v. AZZALI G., «Osservazioni sui reati di pericolo», DOLCINI E. - PALIERO C.E., Studi in onore di Giorgio Marinucci, Milán, Giuffrè, 2006, p. 1335 y ss.

20 El predominio del daño social, a modo de justificación de la intervención penal, es testificado por CANONICO T., Introduzione allo studio del diritto penale, Turín, Editrice Torinese, 1866, p. 297 y ss. Según el autor, pues, es verdadero que el criterio para medir la cantidad de pena consiste en la preciosidad del bien cuyo disfrute se quita al culpable, pero esto no es suficiente para conocer la cantidad política de cada pena, que debe ser más o menos grave sobre la base del mayor o minor daño social que deriva del delito. El autor, además, muestra apreciación para la doctrina según la cual la pena debe ser proporcionada en relación con las circunstancias especiales del individuo, es decir, su carácter, las causas que lo inducieron a delinquir, sus antecedentes, ya que la justicia sustancial requiere que la sanción se adapte a cada individuo de manera particular y diferente. 
que determinadas conductas representan en el panorama de la contemporaneidad, y también, so pena de censura jurídica, la relevancia de los bienes jurídicos constitucionalmente garantizados ${ }^{21}$. Es evidente, pues, que el ejercicio del ius puniendi no puede prescindir de las jerarquías de derechos establecidos en la Constitución. El valor fundamental de la libertad, como en el ejemplo mencionado, puede ser sacrificado única y exclusivamente si en el otro lado de la báscula hay un interés mayor, o por lo menos igual, en términos de importancia, justo sobre la base de los preceptos de la Ley Fundamental.

En conclusión, para tener penas que expresen correctamente adecuación y proporción respecto al desvalor del hecho ${ }^{22}$, es necesario que el recurso a la sanción penal sea proporcionado a la importancia del bien que necesita tutela, tanto con respecto al tipo de bien jurídico a enmarcar en el ámbito penalmente relevante, como a las modalidades de agresión que amenazan la estabilidad de dicho bien ${ }^{23}$.

\subsection{Límites aplicativos del principio de proporcionalidad en abstracto}

El principio de proporcionalidad a nivel abstracto vive con varios y constantes límites operativos que, a veces, impiden su aplicación objetiva a nivel teórico. Como se ha mencionado, razonar acerca de la proporcionalidad verbo tenus es una tarea ardua, ya que la identificación de criterios que corresponden a las lógicas del principio, sin tener un caso concreto en análisis, es compleja. Hay que tomar en consideración tales límites, aun sin poner freno a la instauración de proporcionalidad a nivel legislativo. De hecho, aunque existan estas barreras operativas, no se ha impedido al principio luchar para obtener un reconocimiento casi universal ${ }^{24}$, lo que confirma la centralidad de la proporcionalidad ya en la introducción inicial de la sanción.

21 Las decisiones político-criminales efectuadas por el legislador deben sin duda consistir en un diseño coherente de tutela de los bienes jurídicos, así que no pueda resultar en contradicción con los principios constitucionales que priman sobre el ejercicio del ius puniendi. La política criminal -que no es sino la decisión de intervenir en un determinado sector con los instrumentos propios del derecho penal y, por tanto, la selección de los bienes merecedores de tal intervención- permite la actuación de los principios generales del ordenamiento establecidos en la Constitución. Su función consiste en el mantenimiento del sistema penal de los bienes jurídicos en consonancia con el sistema constitucional de los valores y con el desarrollo de los comportamientos sociales. Así se expresa PAONESSA C., Gli obblighi di tutela penale. La discrezionalità legislativa nella cornice dei vincoli costituzionali e comunitari, Pisa, Edizioni ETS, 2009, pp. 32-33.

22 El poder discrecional que permite la introducción de marcos edictales debe prever estos últimos con arreglo a criterios axiológicos que tengan en consideración, por cierto, el desvalor del hecho a la hora de establecer qualitas y quantum de pena. RONCO M., La legge penale. Fonti, tempo, spazio, persone, Bolonia, Zanichelli, 2010, p. 97.

23 Así se expresan GROSSO C.F. - PELISSERO M. - PETRINI D. - PISA P., Manuale di diritto penale. Parte generale, Milán, Giuffrè, 2013, pp. 65-66. Desde la perspectiva evidenciada, la lesión de un bien más importante justifica una sanción más elevada (el homicido es castigado más gravemente que el furto, porque el bien «vida» pertenece a un rango superior respecto al patrimonio) y el recurso a particulares modalidades agresivas pueden condicionar la diversidad del reproche penal (una agresión al patrimonio mediante engaño es menos grave que una mediante violencia o amenaza). El principio de proporcionalidad, sin embargo, expresa no sólo la exigencia de la adecuación de la pena respecto a la gravedad del hecho, sino que constituye el criterio general de congruencia de los instrumentos normativos respecto a las finalidades a perseguir.

24 En este sentido, v. PALAZZO F., Corso di diritto penale, op. cit., p. 31. El autor afirma que las mayores dificultades operativas del principio de proporción derivan de la imposibilidad de identificar un criterio de precisión, un parámetro que permita comparar dos grandezas absolutamente heterogéneas, como las de la intensidad aflictiva de la sanción y de la gravedad del ilícito. Es difícil, dicho en otro modo, encontrar un criterio que permita explicar de manera racional la motivación por la cual un determinado quantum está aparejado a un delito específico. El autor utiliza, para demostrar la veracidad de su tesis, la pena establecida para la violación del domicilio en el sistema penal italiano: evidencia, con este ejemplo, la inexistencia de un parámetro objetivo que pueda legitimar una sanción de privación de libertad de quince días hasta tres años, en lugar de una pena homóloga de quince días a 
El hecho delictivo, por definición, debería leerse de manera inequívoca y segura a garantía de la seguridad jurídica por un lado, y de la tutela del individuo hacia una injerencia estatal ilícita por otro ${ }^{25}$. Sin embargo, la «revolución penológica» de la Ilustración, que ha velado por que la sanción se apartase del modelo liberal clásico, ha llevado a una seria individualización de la pena ${ }^{26}$, asegurando el respeto de la responsabilidad penal personal, y también ha llevado a la introducción de elementos de indeterminación de la sanción penal ${ }^{27}$. De hecho, la introducción del sistema individual de la pena no ha encontrado la justa ponderación entre flexibilidad del tratamiento y garantías individuales, permitiendo así la difusión normativa de piezas vagas e inciertas con respecto a la sanción.

Con derivación directa de la individualización de la pena, el principio de proporcionalidad sufre el empirismo que lo caracteriza y las dudas que penden en torno a su impostación dogmática a nivel abstracto ${ }^{28}$. Entre delito y pena, de hecho, no existe alguna relación de tipo natural. Cada conexión entre los dos conceptos es el resultado de una teoría -también de tipo puramente lógico- que los vincula con arreglo a una sistemática de causa y consecuencia. Hay que mencionar, al respecto, que ontológicamente una conducta en violación de la ley (en este caso, ley penal) no incluye en sí el modelo de la sanción. Aunque una norma penal pierda su significado si no lleva una sanción aparejada, esto no quiere decir que no pueda existir una disposición normativa penal carente de pena. Para ejemplificar, tómese en consideración la hipótesis de que la conducción de camiones por parte de menores de veintiuno años sea una conducta típica penalmente relevante. Esta representa una eventualidad realizable desde el punto de vista natural. No implica de manera automática que a dicho hecho delictivo le consiga una sanción. En otras palabras, a nivel ontológico, la tipificación de la conducta delictiva no postula la exigencia de una sanción; a nivel lógico, sin embargo, hay que considerar que, a falta de la previsión normativa de la pena, la entera norma penal perdería su connotación disuasoria, por lo tanto no beneficiaría al alcance del objetivo predeterminado. No es por causa de esta exigencia lógica, por cierto, que la prohibición de conducción de camiones por parte de menores de veintiuno años dejaría de ser una norma jurídica válida.

cuatro o cinco años. A pesar de dicho límite inherente a la esencia del principio de proporcionalidad, la proporción ha llegado a ser un principio casi universalmente aceptado.

25 Subraya la necesidad de una tipificación clara e inteligible DONELLI F., «Circostanze del reato e 'tipicità negata' nella recente riforma del diritto penale degli stupefacenti», Rivista italiana di diritto e procedura penale, 2016, p. 1879 y ss., § 2.1. El autor, con respecto a la tipificación de hechos delictivos relativos a las sustancias estupefacientes, denuncia una especie de ensañamiento que implica la atribución de un significado distorsionado a palabras que quieren decir otra cosa, descuidando la fundamental importancia del momento inicial en que el hecho debería proponerse al intérprete como la primera y más segura guía para ligar el precepto a un único significado.

26 FRANCHI B., «Il principio individualizzatore nell'istruttoria penale», La scuola positiva, 1900; FEIJOO SÁNCHEZ B.J., «Individualización de la pena y teoría de la pena proporcional al hecho. El debate europeo sobre los modelos de determinación de la pena», InDret - Revista para el análisis del derecho, 2007.

27 La reflexión sobre la revolución penológica, que ha permitido el paso de un modelo sancionador liberal al modelo individual, pertenece a PIFFERI M., L'individualizzazione della pena. Difesa sociale e crisi della legalità penale tra Otto e Novecento, Milán, Giuffrè, 2013, pp. 284-286. El autor enmarca el problema de la individualización de la pena a nivel constitucional, ya que influye en la separación de los poderes, en la legalidad de la pena y en los derechos individuales.

28 El más grave defecto de la concepción proporcional de la pena es la imposibilidad de indicar racionalmente la razón por la cual a un determinado nivel de gravedad del delito debe corresponder necesariamente un determinado nivel de pena. Así se expresa STELLA P., Pena e politica criminale. Aspetti teorici e casi pratici, Milán, Giuffrè, 2008, p. 129. 
Por dicha razón, la falta de nexo natural entre delito y sanción no configura una condición que obsta al hecho de que, una vez introducida una pena como consecuencia de un hecho típico, ella debet commensurari delicto ${ }^{29}$. Más bien, la inexistencia de este tipo de conexión evidencia que el cumplimiento, por parte de la sanción, de la obligación intrínseca de respetar el principio de proporcionalidad no puede evaluarse según criterios naturales objetivos, sino sólo a través de parámetros pragmáticos basados en evaluaciones políticas y de oportunidad.

La imprecisa correspondencia entre delito y pena impone al principio de proporcionalidad un papel bastante ambiguo ${ }^{30}$, endureciendo el sistema con artimañas hermenéuticas que -en abstracto- ayuden la configuración del mismo. La preocupación más relevante, procedente del enigmático papel desempeñado por el principio de proporcionalidad, concierne sin duda el fomento de una jurisprudencia creativa que se generaría en detrimiento de la actividad legislativa ${ }^{31}$. El utilizo de parámetros vagos y genéricos, de hecho, acentúa la libertad del juicio de constitucionalidad y, por tanto, permite el traslado del poder legislativo en las manos de los órganos jurisdiccionales, tanto ordinarios como constitucionales. Es frecuente la referencia negativa a dicho riesgo de abuso jurisdiccional con la presunta solución de constitucionalizar el derecho penal utilizando únicamente conceptos precisos y no distorsionables, para que se proteja la lógica jurídica de los ataques de la técnica de la concreción política de los conceptos vagos e incertos ${ }^{32}$.

29 FERRAJOLI L., Diritto e ragione. Teoria del garantismo penale, Bari, Laterza, 2008, pp. 395-396. Según el autor, el hecho de que entre pena y delito no exista alguna relación natural no excluye que la primera deba ser adecuada al segundo. Al contrario, el carácter convencional y legal del nexo retributivo que liga a sanción al ilícito penal exige que la decisión de la cualidad y cantidad de la pena sea llevada a cabo por el legislador y por el juez en relación con la naturaleza y la gravedad del hecho. El principio de proporcionalidad expresado por la antigua máxima «poena debet commensurari delicto» es un corolario de los principios de legalidad y retribución. Con estas palabras el autor precisa el carácter convencional -y por tanto no ontológico- de la sanción en relación con el hecho delictivo y reitera que esta última debe ser proporcionada a la conducta cometida por el reo, aunque existan exclusivamente criterios pragmáticos basados en evaluaciones ético-políticas o de oportunidad, para establecer la cualidad y cantidad de pena adecuada a cada delito. Desde esta perspectiva, la evaluación del quomodo y del quantum de pena se convierte en un problema moral y político, como ya observaba BENTHAM J., «Théorie des peines et des récompenses», BENTHAM J., Oeuvres de Jérémie Bentham, Bruselas, 1840. Al respecto, v. también MOCCIA S., Il diritto penale tra essere e valore. Funzione della pena e sistematica teleologica, Nápoles, Edizioni Scientifiche Italiane, 1992, p. 215 y ss.

30 La expresión «papel ambiguo», con respecto a la idea de proporcionalidad, es de EUSEBI L., «Su violenza e diritto penale», Antigone, 2016, p. 51 y ss. Del mismo modo se expresa también PULITANÒ D., «Sulla pena. Fra teoria, principi e politica», Rivista italiana di diritto e procedura penale, 2016, p. 650. El autor identifica la relación entre delitos y penas, cuyo principio rector que atraviesa la historia es la proporción. A falta de criterios precisos de correspondencia entre delito y pena, también la idea de proporción se arriesga a desempeñar un papel ambiguo. Si se liga a la ideología retributiva, podría corroborar la idea de que exista y se pueda identificar la pena correspondiente a la gravedad del delito; el efecto sería el endurecimiento del sistema. Si se liga al principio de igualdad/razonabilidad, ideal regulador de un derecho penal sin arbitrariedad, la proporción se consideraría una condición mínima de coherencia intrasistemática y de coherencia con los principios materiales del sistema de delitos y penas. Desde el punto de vista del autor, la idea de proporción reenvía a una relación de gravedad entre diversos delitos y sirve como comparación entre varias pena, no puede actuar como criterio de por sí suficiente.

31 Dicha preocupación pertenece a KELSEN H., «La garantía jurisdiccional de la Constitución», Anuario iberoamericano de justicia constitucional, 2011, pp. 249-300. El autor aconseja insertar en los preceptos constitucionales disposiciones normativas más analíticas y ricas de detalles, a fin de eliminar todo tipo de incertidumbre y evitar que la tasa de creatividad de la jurisprudencia pueda prevalecer sobre el poder legislativo. En contra de lo expuesto por el autor, el consejo es criticado por ser el resultado de una ingenuidad del filósofo por parte de PINTORE A., I diritti della democrazia, Bari, Laterza, 2004, p. 121. Al respecto, v. también PINTORE A., «Democrazia senza diritti. In margine al Kelsen democratico», Sociologia del diritto, 1999, p. 27 y ss.

32 La solución mencionada es criticada negativamente por FIANDACA G., «Legalità penale e democrazia», op. cit., p. 1265 y ss. El autor cuestiona la realizabilidad de dicho iter constitucional puesto idealmente a tutela del derecho 
Cabe concluir que el necesario utilizo de la hermenéutica jurídica para interpretar correctamente el principio de proporcionalidad, dados su carácter empírico y el riesgo de una ambigüedad progresiva de las normas, debe siempre tener en consideración la fundamental relación que existe entre la prescripción abstracta, establecida por el legislador, y los contextos humanos a los que ella se refiere ${ }^{33}$. Desde esta perspectiva, dicha relación sería condición de efectividad y de validez de la norma penal sancionadora.

Es también responsabilidad de esta correlación que el principio de proporcionalidad refleja los caracteres de instabilidad y mutabilidad, ya que las circunstancias sociales empíricas subyacentes varían a menudo y no permiten una constante evaluación homogénea de las normas con respecto a la proporción entre delito y pena.

\subsection{La función del principio de proporcionalidad entre exigencias democráticas y discrecionalidad política}

El principio de proporcionalidad puede actuar como cuadro de más ámbitos de acción heterogéneos en función de la perspectiva desde la cual se desarrolla el análisis. Desde un punto de vista estrictamente funciona ${ }^{34}$, el criterio de proporción representa el eje para obtener el resultado de prevención general ${ }^{35}$. Es posible afirmar así que la adecuación del medio sancionador a la finalidad predeterminada de la intervención penal específica desempeña el papel fundamental de mediador entre el sacrificio sufrido por el reo y la finalidad disuasoria que la pena encarna.

Para que la colectividad deje de cometer hechos delictivos, es oportuno que las relativas sanciones sean proporcionadas a las conductas típicas. Si una pena fuese desproporcionada por defecto, de hecho, el efecto general preventivo sería casi nulo ${ }^{36}$. La superación, claramente ad inferos, del límite mínimo de pena necesaria para luchar contra un fenómeno delictivo no permitiría al eventual sujeto agente percibir como intimidante

penal de las injerencias ilegítimas de los órganos jurisdiccionales. Según el autor, la ciencia penal que actuase como guía para fundamentar más firmemente el derecho penal ya no sería, quizás, una ciencia. A lo mejor, según el autor, se trataría de una auctoritas doctorum desvinculada de las normas escritas.

33 LAVAGNA C., «Ragionevolezza e legittimità costituzionale», LAVAGNA C., Ricerche sul sistema normativo, Milán, Giuffrè, 1984, p. 645 y ss.

34 La sanción penal asume un carácter polivalente en función de la finalidad que se prefija y del ilícito que acompaña. Dada dicha polivalencia, resulta oportuno coordinar las diversas funciones para evitar que el prevalecer de una finalidad anule otra. El sistema sancionador, pues, debe ser flexible, justo porque es potencialmente idóneo a moldear cada instituto en función de las diversas exigencias que las opciones legislativas implican. Así se expresan GROSSO C.F. - PELISSERO M. - PETRINI D. - PISA P., Manuale di diritto penale, op. cit., pp. 594-595.

35 KAPLAN J. - WEISBERG R. - BINDER G., Criminal Law. Cases and Materials, Nueva York, Aspen Publishers, 2008, p. 80. Los autores, recordando la matriz no sólo retributiva del principio de proporcionalidad, afirman la necesidad de este último con respecto a la finalidad disuasoria de la pena con las siguientes palabras: «the concept of proportionality is not necessarily or exclusively retributivist. Recall that other theories of punishment imply limiting principles. The utilitarian rationales for punishment may also be thought to yield principles of proportionality that preclude pointless punishment. Thus deterrence requires that sentences be «proportionate» to the harm and deterrability of the offender's type of crime».

36 Desarrolla este análisis PALAZZO F., Corso di diritto penale, op. cit., p. 31. El autor afirma que, desde una perspectiva funcional, la proporción puede ser considerada, en primer lugar, un criterio de individuación de la pena necesaria y suficiente - en cuanto a cualidad y cantidad- para obtener el resultado de prevención general (positiva o negativa) perseguido. Desproporcionada por defecto sería, por tanto, la pena que por especie y magnitud apareciera a priori totalmente inadecuada a producir el efecto disuasorio. Desproporcionada por exceso sería, en cambio, la pena cuyas especie y magnitud aparecieran inútilmente exageradas respecto a lo indispensable para el alcance de aquellos resultados. Desde esta perspectiva, la proporción se pone como un criterio de adecuación del medio a su fin, más que como una comparación cuantitativa entre entidades diferentes. 
la potestad punitiva estatal, así que él no se adaptaría al precepto legislativo y con mayor probabilidad acogería la condición de reo.

Para ejemplificar concretamente el concepto, basta con pensar en una reducción al absurdo. Imagínese, pues, que el ordenamiento prevea exclusivamente la pena pecuniaria para la comisión de un homicidio. A pesar de la motivación con la que actúe, resulta probable que, desde un punto de vista comparativo, el autor del delito considere más predominante el beneficio (económico o social) conseguido con el homicidio que la desventaja constituida por la sanción pecuniaria. Si, en cambio, la pena fuese proporcionada a la gravedad del hecho, el beneficio que el reo obtendría con la comisión de la conducta típica se consideraría casi nulo frente al sacrificio futuro en el caso de condena. La eventualidad de la condena no es un elemento irrelevante a efectos de la evaluación personal que el sujeto agente realiza a la hora de poner en marcha una conducta penalmente relevante. La pena debe sin duda ser capaz de intimidar al eventual reo, pero dicha intimidación resulta vana si no existen mecanismos de condena operativos y eficientes ${ }^{37}$. El que quiera realizar un hecho típico, de hecho, debe ver como disuasoria la fuerza de la sanción, la cual no consiste sólo abstractamente en una previsión legal, sino también en un aparato jurisdiccional que garantice la celeridad y la justicia de los procesos.

Al mismo tiempo, si una pena fuese desproporcionada por exceso, el grupo social no dudaría en comprender que la potestad punitiva estatal representaría una represión excesiva que, con la mirada vuelta a la historia maestra, es índice incuestionable de un poder totalitario. También en este caso el efecto general preventivo, si no se anula, se ve distorsionado. El fundamento de la prevención general, de hecho, está arraigado en la convivencia civil y pacífica. Está encaminado, pues, a evitar que se cometan delitos a fin de conducir una vida comunitaria segura y garante de los bienes jurídicos primarios. Si la represión estatal fuese excesiva, la convivencia segura y pacífica no representaría ya el ideal de un Estado democrático, sino más bien la ambición de un poder opresor, lo que desde luego no está entre los objetivos de la teoría general preventiva.

Cabe señalar, además, que desde el punto de vista funcional una desproporción -por exceso o por defecto- de la pena distorsionaría también su propia finalidad de reiserción social, prevista a nivel constitucional. Si la sanción fuese desproporcionada por defecto, es claro que dicha finalidad se aniquilaría, porque ya a nivel normativo la conducta no interpretaría el real desvalor del hecho. $\mathrm{Si}$, al contrario, fuese desproporcionada por exceso, la pena no se consideraría conforme a los criterios básicos de justicia por parte de los ciudadanos. Los destinatarios de la norma, pues, rechazarían la validez del ordenamiento jurídico ${ }^{38}$ y esto, por tanto, obstaculizaría el correcto funcionamiento de la Constitución.

Desde un punto de vista no ya funcional, sino de garantía, el principio de proporcionalidad de la pena representa un criterio con el cual es posible comprobar la presencia de un equilibrio dentro del sistema sancionador ${ }^{39}$. De hecho, si se analiza la

37 Para profundizar el tema, v. BIANCHETTI R., La paura del crimine. Un'indagine criminologica in tema di mass media e politica criminale ai tempi dell'insicurezza, Milán, Giuffrè, 2018. El autor, desde un punto de vista criminológico, dialoga con la ciencia penal para analizar los efectos intimidantes del crimen en los individuos.

38 PALAZZO F., Corso di diritto penale, op. cit., p. 32.

39 MANES V., Il giudice nel labirinto. Profili delle intersezioni tra diritto penale e fonti sovranazionali, Roma, Dike, 2012, pp. 144-145. El autor explica que en el ámbito penal el principio de proporcionalidad se afirma ante todo como criterio de control sobre el equilibrio sancionador y aspira a examinar más detenidamente el fundamento de la incriminación, su razonabiliadad respecto a valores y fines. 
proporción en calidad de garantía de los derechos y de las libertades del individuo, no puede eludirse su carácter restrictivo del poder represivo estatal ${ }^{40}$. Es posible que el Estado ejerza su ius puniendi de manera totalmente arbitraria, al menos en un primer momento, ya que el legislador actúa en completa discrecionalidad y, prescindiendo del escrutinio posterior del control jurisdiccional, las normas penal adquieren vigor desde su introducción en el panorama jurídico. El principio de proporcionalidad, a fin de garantizar la tutela de las exigencias del ciudadano, desempeña el papel central de moderador de la discrecionalidad legislativa, ya que es el criterio que permite evitar que el nivel represivo del Estado supere los límites infranqueables de los ordenamientos democráticos.

La proporción, pues, si por un lado encarna las exigencias democráticas básicas del ordenamiento moderno ${ }^{41}$, no representa sólo un principio de justicia, sino también un criterio político que guía las decisiones del órgano legislativo. Aunque no se pueda aplicar sobre la base de criterior rígidamente científicos ${ }^{42}$, ella representa la piedra angular en la implementación de las sanciones penales dentro del ordenamiento. El legislador, así, deberá tomar en consideración los criterios constitutivos de la proporcionalidad a la hora de ejercer la opción penal, a fin de determinar correctamente la construcción de un ilícito y la tipología -cualitativa y cuantitativa- de sanción que lo acompaña ${ }^{43}$. Así es como, tras garantizar eficazmente la tutela del individuo frente a una injerencia estatal excesiva, la

40 Al respecto, v. PALAZZO F., Corso di diritto penale, op. cit., p. 32. Desde una perspectiva de garantía, la proporción desempeña un papel central de criterio que contiene las medidas políticas establecidas por el legislador en materia penal, al menos en un Estado liberal-democrático. Aunque el principio no pueda ofrecer certezas matemáticas sobre el quantum de pena a imponer, es claro que puede servir como límite a la injerencia estatal para evitar que se desarrollen excesos sancionadores capaces de alterar el equilibrio entre el ius puniendi del Estado y las orientaciones de la sociedad contemporánea. El principio de proporcionalidad, pues, vela por que el legislador no introduzca niveles represivos desproporcionados respecto a las evaluaciones sociales actuales, ya que si lo hiciera, las penas sólo podrían reflejar las presuntas exigencias de la razón política. En este sentido, el autor bien expresa que el principio en cuestión constituye un límite al poder represivo estatal, más que un criterio de correspondencia cuantitativa entre dos «males», la conducta típica y la sanción.

41 El valor de la proporcionalidad expresa sin duda una fundamental exigencia de justicia, propia de cada ordenamiento democrático. HERLIN-KARNELL E., The Constitutional Dimension of European Criminal Law, Oxford, Hart Publishing, 2012, p. 127, no duda de que «the principle of proportionality is better reflected in the very notion of justice». Sobre el sentimiento de iustitia y la importancia del principio de proporcionalidad desde una perspectiva social y filosófica, v. GIRALDI A., «La proporcionalidad de la pena en el ordenamiento español: elaboración doctrinal y evolución jurisprudencial», La Ley Penal, 2018, § II.1.

42 Se refiere al principio de proporcionalidad como criterio MANZINI V., Trattato di diritto penale italiano, op. cit., p. 5. Aquí se indica la objeción que sufre la proporción en materia penal: dicho principio, en la conminación abstracta de las penas, no puede aplicarse con arreglo a reglas científicas precisas e inmutables, por tanto no puede representar un canon a respetar en el iter legislativo. Para desmentir dicha tesis, sin embargo, el autor señala que en materia de relaciones sociales nada posee rigor científico. De hecho, cada concepto es el resultado de convenciones empíricas, elaboradas y arregladas gracias al trabajo de la ciencia. Por esta razón, a pesar de la ausencia de una precisión absoluta, el principio de proporcionalidad puede desempeñar el papel central que se le atribuye. Se pone a garantía de los derechos del ciudadano, interpreta las exigencias sociales para evitar efectos autoritarios ilícitos del poder estatal.

43 Con respecto a la opción penal, hay una corriente doctrinal que, enmarcando la proporcionalidad como una de las dos caras del principio de subsidiariedad, apoya la tesis de que la intervención del derecho penal está subordinada a la ineficiencia de los remedios extrapenales. Cabe destacar que según BARLETTA A., La legalità penale tra Diritto dell'Unione europea e Costituzione, Nápoles, Jovene, 2011, p. 133, en ambas sus acepciones el principio en cuestión tiende, en vía teórica, a reducir la intervención legislativa y la opción penal, la cual ha de considerarse con arreglo a la concepción lisztiana (la intervención del derecho penal es tanto la construcción del ilícito como de la tipología penal). Asi DONINI M., "Sussidiarietà penale e sussidiarietà comunitaria», AA.VV., Coord. MOCCIA S., Ambito e prospettive di uno spazio giuridico-penale europeo, Nápoles, Edizioni Scientifiche Italiane, 2004, p. 129. 
aplicación del principio de proporcionalidad puede permitir a la ley huir de riesgos significativos, entre los cuales consta la introducción de penas excesivamente severas ${ }^{44}$.

La actuación del órgano legislativo es dominada por una discrecionalidad que permite al mismo establecer sanciones con respecto a determinados hechos delictivos utilizando la máxima libertad en las decisiones cualitativas y cuantitativas sobre la pena, aun respetando los principios constitucionales. A veces, sin embargo, el fenómeno de la discrecionalidad legislativa puede resultar en una indeterminación de la norma, ya que los elementos considerados por el legislador pueden dar lugar a ambigüedades en el momento de la interpretación jurídica ${ }^{45}$. Dicho mecanismo de indefinición de la norma es, como regla general, el resultado de la lógica subyacente a la hermenéutica jurídica, que permite atribuir a las disposiciones normativas los significados más heterogéneos.

Sin embargo, de vez en cuando la discrecionalidad penal resulta en una indeterminación no sólo fisiológica, sino también intencional de la norma abstracta ${ }^{46}$. La voluntas legislatoris es, pues, diversa en función de cada actuación llevada a cabo con la intervención normativa. Puede ocurrir que el legislador desee dejar en las manos de los operadores jurídicos, incluidos los jueces, el futuro de la norma penal. Dicho mecanismo, al menos, distorsiona las consideraciones que se hicieron al principio, por las cuales, en un Estado de Derecho, es la determinación normativa que ha de primar sobre la discrecionalidad judicial, nunca al revés ${ }^{47}$. Por esta razón, sería oportuno que la discrecionalidad legislativa no excediese de los límites que evitan la producción de alteraciones sistemáticas aptas para viciar el sistema entero.

El uso indebido de la discrecionalidad legislativa, que permite eludir la necesidad de proporción entre delito y pena ${ }^{48}$, puede generar también otra distorsión de la disposición normativa y, en su conjunto, del sistema jurídico. Si la libertad discrecional del legislador estuviera desvinculada de todo tipo de control, sería posible que se instaurase el mecanismo denominado penal populism, el cual autoriza las normas a acercarse de manera desmesurada a la opinión pública y al valor social que cada hecho asume en la época contemporánea ${ }^{49}$. Dicha descontextualización de las normas, o sea un alejamiento de éstas de la lógica

44 VENEZIANI P., «La punibilità. Le conseguenze giuridiche del reato», GROSSO C.F. - PADOVANI T. PAGLIARO A., Trattato di diritto penale. Parte generale, Milán, Giuffrè, 2014, p. 52, subraya la preocupación del reproche penal que consiste en penas con particular y progresiva severidad.

45 La discrecionalidad legislativa nace y se desarrolla en diversos vicios del iter legis, que dan lugar a defectos de las normas bajo varios puntos de vista. Al respecto, v. amplius MESSINA S., La discrezionalità nel diritto penale, Roma, Edizioni dell'Ateneo, 1947, p. 16, el cual considera la discrecionalidad un defecto de taxatividad de la norma penal.

46 En este sentido, v. CORDERO F., Le situazioni soggettive nel processo penale, Turín, Giappichelli, 1956, p. 161. El autor destaca la voluntad del legislador de dejar en una esfera de abstracción las posibles interpretaciones de la disposición normativa.

47 El juez no puede ser artífice de la norma, sólo puede aplicarla. Así CADOPPI A. - CANESTRARI S. - MANNA A. - PAPA M., Trattato di diritto penale. Parte generale, vol. III, Torino, Utet, 2014, p. 202. A este respecto, se reenvía a la máxima por la cual el juez sólo es boca de la ley (v. supra, sub nota 5).

$48 \mathrm{La}$ relevancia del principio de proporcionalidas es mayor en función de cuanto mayor es el espacio de discrecionalidad reconocido al órgano agente, es decir, el legislador. Señala esta consideración GALETTA D.U., Principio di proporzionalità e sindacato giurisdizionale nel diritto amministrativo, Milán, Giuffrè, 1998, pp. 8586 , con respecto a la aplicación de la proporcionalidad en ámbito comunitario. Según la autora, el principio de proporcionalidad se halla estrictamente vinculado al precepto normativo abstracto, más que a los actos concretos, por lo tanto vive en simbiosis con la actuación del legislador.

49 La expresión inglés «populismo penal» es propia de HERLIN-KARNELL E., The Constitutional Dimension of European Criminal Law, op. cit., p. 130. El autor expresa con eficacia que la legitimación del derecho penal 
constitucional de los delitos, vicia el sistema autorizando la negociación arbitraria de los derechos del individuo afectados por las normas penales. Es claro, pues, que la ley penal conmina sanciones que se concretan en una restricción de los derechos del reo; para que tal restricción sea conforme a los principios constitucionales, incluido el principio de proporcionalidad de la pena, es necesario que se tome en consideración la opinión social del hecho delictivo, pero ya no es suficiente. Por ejemplo, podría resultar desproporcionada una pena que castigase un hecho considerado ilícito por la sociedad en el caso de que el bien jurídico tutelado no mereciese protección alguna a nivel constitucional ${ }^{50}$.

La desproporción penal generada por una deferencia excesiva hacia la opinión pública es un síntoma preocupante del mismo modo que el fenómeno inverso, llamado derecho penal promocional. En efecto, puede ocurrir que el legislador decida inculcar en la sociedad valores que no le pertenecen, utilizando al efecto el mecanismo sancionador penal. Piénsese, por ejemplo, al delito de adulterio, hoy inexistente en el ordenamiento penal español ${ }^{51}$. Dada la concepción social actual de la conducta adulterina, sería desproporcionado reintroducir una sanción penal relativa a este hecho hoy atípico. La tutela del vínculo matrimonial sigue siendo una prerrogativa del ordenamiento español, y sin embargo -debido al cambio de circunstancias sociales- no se detecta la necesidad de proteger ese bien jurídico mediante el derecho penal. Por lo tanto, si el legislador -aun respetando los preceptos constitucionales- decidiera promover la imposición de sanciones penales manifiestamente sueltas del valor social atribuido al hecho, la intervención legislativa sería ilegítima ${ }^{52}$.

\subsection{Las posibles técnicas de normación a garantía del principio de proporcionali- dad de la pena}

El análisis desarrollado acerca del principio de proporcionalidad en abstracto confirma sin duda su preponderancia en la actividad de normación del legislador. Esta última, de

requiere mucho más que la simple aprobación pública. En otras palabras, «there are some fundamental rights and some crucial axioms in criminal law theory including the imperative of legality and the right to fair trial - as discussed above - which are absolute rights and hence not negotiable rights. But when dealing with criminal law and human rights protection it is necessary to adopt a critical stance and ask what concepts we are really dealing with and what it means for the development of an EU criminal law policy to rely on them. Looking at criminal law in the national arena, history tells us that the public often tend favour a more severe criminal law system (the tough-on-crime argument) despite the fact that further legislation does not always make the system more effective. Sound empirical research plays an important function here, but should be far from the only concern. Thus, it is important to move beyond mere opinion polling. In other words, any empirical research needs to be very carefully examined and collected».

50 Con esto se quiere decir que sea cual sea la opinión social, el derecho penal no está obligado a adecuarse a ella necesariamente. Si, irónicamente, una determinada comunidad aceptara como lícito el homicidio, el ordenamiento jurídico no debería adecuarse y legitimar este delito. Más bien, siempre hay que tomar en consideración la opinión social, pero respetando los principios fundamentales del ordenamiento, dictados por la Carta constitucional.

51 En España el adulterio fue despenalizado a través de la Ley 22/1978, de 26 de mayo, sobre despenalización del adulterio y del amancebamiento, que entró en vigor el 19 de junio de 1978.

52 La delegitimación del derecho penal promocional es directa consecuencia del carácter pre-normativo de los bienes jurídicos. En este sentido, v. GROSSO C.F. - PELISSERO M. - PETRINI D. - PISA P., Manuale di diritto penale, op. cit., p. 67. Según los autores, los principios constitucionales desempeñan un papel de límite a las instancias represivas. El legislador, pues, no podría inculcar, a través de la sanción penal, el respeto de valores en los cuales la comunidad no cree o cuya tutela considere desproporcionado el sacrificio de la libertad personal. El reproche penal no puede justificarse sólo con el merecimiento de pena en relación con el bien y las modalidades de agresión, porque el sacrificio impuesto a la libertad personal por parte de la sanción penal requiere que exista también una efectiva necesidad de pena. Dicho de otro modo, es necesario que resulten ineficaces otros instrumentos de tutela menos aflictivos. 
hecho, siempre debe acoger generosamente los estándares de la proporcionalidad a la hora de establecer los delitos y sus relativas penas. El órgano legislativo se encarga de identificar esas sanciones para que constituyan una especie de escalation de los bienes jurídicos penalmente protegidos. Se habla, al respecto, de la configuración de un «tarifario de las penas $\rangle^{53}$, que cuantifica de alguna manera el valor que la sociedad atribuye a los varios bienes jurídicos en un determinado momento histórico. Justo por esto, el legislador no puede prescindir de la evaluación de idoneidad, necesidad y ponderación que caracteriza la impostación dogmática del principio de proporcionalidad.

La garantía de proporcionalidad de una determinada pena no puede asegurarse por métodos formales o procesales ${ }^{54}$. De hecho, el examen de los tres niveles no puede realizarse a través de automatismos convencionales como un determinado quorum necesario para aprobar una ley. Más bien, se necesita un procedimiento a través del cual sea posible instaurar un debate más amplio sobre el contenido de la norma, para que el legislador pueda analizar todos los caracteres de la proporcionalidad. Los instrumentos encaminados a su respeto deben ser mecanismos dotados de la justa complejidad estructural, aptos para permitir un examen analítico de la sanción que dé lugar a un resultado satisfactorio.

A nivel de técnica legislativa, es posible analizar, por ejemplo, algunos de los remedios no ya formales, sino sustanciales, que apoyan la actuación efectiva del principio de proporcionalidad. En primer lugar, es oportuno afirmar que la mayoría de la doctrina está de acuerdo en postular la necesidad de textos normativos no genéricos, sino más vinculados, una y otra vez, al caso concreto en análisis. En lugar de interpretar las leyes generalizando prima facie sus contenidos, sería mejor practicar una actividad que permitiese añadir precisiones, distinciones y ecepciones para que pueda conducirse la disposición legal a las exigencias empíricas de la situación concreta ${ }^{55}$.

En sentido más amplio, esta no generalización -o mejor especificación- de las normas permite examinar, en segundo lugar, la fórmula legislativa del delito circunstanciado. Yuxtaponer una circunstancia, sea cual sea su naturaleza, a un delito representa una modalidad para que en el caso en cuestión sea posible personalizar el efecto de la norma ${ }^{56}$. Es superfluo reiterar que cada hecho natural constitutivo de delito lleva en sí caracterís-

53 FERRAJOLI L., Diritto e ragione, op. cit., p. 399. El autor indica la pluralidad de factores que influyen sobre las decisiones del legislador, subrayando que estas configuran una especie de «tarifario de las penas» $\mathrm{y}$, por tanto, de los bienes penalmente protegidos por un determinado ordenamiento, así que el sistema de las penas señala la escala de los valores históricamente determinada en una sociedad, tras su grado de autoritarismo, tolerancia y humanidad. De modo claro el autor explica que, aunque sea imposible medir la gravedad de un delito específico, es posible, con arreglo al principio de proporcionalidad, afirmar que desde el punto de vista interno, si dos delitos se castigan con la misma pena se consideran de igual gravedad, mientras que si la pena prevista para un delito es más severa que la de otro delito, el primero se considera más grave del segundo.

54 Un remedio formal-procesal es obviamente insuficiente para garantizar principios complejos, como la proporcionalidad, pero también la racionalidad del derecho penal. V. amplius FIANDACA G., «Legalità penale e democrazia», op. cit., p. 1271. El autor evidencia que el reflejo automático de una mayoría numérica no puede representar el criterio con el cual se confiere racionalidad y credibilidad al derecho penal. El mismo razonamiento puede aplicarse con respecto a la proporción de la pena.

55 PACE L., «Gli automatismi legislativi nella giurisprudenza costituzionale», www.gruppodipisa.it, 18 de septiembre de 2014, p. 13. La opción del legislador de introducir precisiones dentro del texto normativo evitaría que se aplicara con generalidad y vaguedad.

56 La aplicación de las circunstancias, básicamente, permite atenuar la rigidez de las previsiones legislativas para adaptarse de manera más realista al caso concreto. Sobre la adecuación individualizada y proporcionada de la pena, v. LATTANZI G. - LUPO E., Codice penale. Rassegna di giurisprudenza e di dottrina, vol. I, Milán, Giuffrè, 2015, pp. 472-473. Aquí se encuentra una amplia literatura doctrinal y jurisprudencial al respecto. 
ticas muy diversas y carentes de unicidad. Más conductas típicas puestas en marcha por uno o más sujetos agentes, aun si de la misma naturaleza o clasificación normativa, cuentan con la heterogeneidad más absoluta de sus peculiaridades. Es imposible pensar que, por ejemplo, dos conductas fraudulentas tengan necesariamente las mismas modalidades de ejecución, la misma intensidad y la misma gravedad. Es suficiente un toque lógico para comprender que, ex plurimis, la diversidad del sujeto agente, del contexto y del objeto del fraude contribuyen a determinar la diferencia entre cada conducta típica, aunque sean de la misma species normativa.

Habida cuenta de esta premisa, circunstanciar el delito viene a ser indispensable. De hecho, la inclusión de circunstancias a nivel normativo permite al juez aplicar la ley de manera más correcta, es decir, adaptada a las peculiaridades de cada sujeto y cada hecho que se le imputa. El delito circunstanciado, pues, produce una mejor individualización de la pena ${ }^{57}$, que a su vez significa moldear una pena sobre la estructura efectiva del caso concreto y, por tanto, contribuir a que la sanción sea proporcionada al hecho delictivo. En este sentido, el papel que juegan las circunstancias es significativo, ya que permiten que el juez, a lo largo de un proceso regular, aplique la pena proporcionalmente, en función de las exigencias del caso. En la hipótesis de un hecho castigado con la pena de reclusión cuya duración se extiende entre un mínimo y un máximo edictal, si el juez no pudiera fundamentar su recorrido lógico en unas circunstancias predeterminadas -porque ausentes-, su decisión beneficiaría de menor inteligibilidad y se acercaría el riesgo de no poder huir del arbitrium iudicis ${ }^{58}$. Al contrario, en el caso de que tenga a disposición unos parámetros predeterminados, sus inferencias lógicas gozarán de mejor estabilidad y, a lo mejor, comprensión, lo que permite un control ineludible de su amplia discrecionalidad.

Cabe recordar, sin embargo, que el utilizo de las circunstancias en la ordenación de las conductas no es siempre y automáticamente un índice de mejor aplicación de la sanción respecto al caso concreto ${ }^{59}$. De hecho, si las circunstancias gozan de un poder enorme frente al delito, también el juez beneficia de un poder muy amplio -i.e. su discrecionalidad-frente a las circunstancias ${ }^{60}$. Se trata de factores que, si usados anormalmente

57 Así se expresa DE VERO G., Circostanze del reato e commisurazione della pena, Milán, Giuffrè, 1983, p. 129. Según el autor, el delito circunstanciado promueve realmente una mejor individualización de la pena respecto al delito simple, porque introduce un más racional proceso de enucleación del quantum adecuado al caso específico. No hay que subestimar, pues, la importancia que las circunstancias presentan dentro de la estructura de la norma, a pesar de las varias dificultades que a veces atribuyen arbitrariedad completa a la aplicación de las circunstancias.

58 Sobre la individualización de la pena, en el marco del balance entre discrecionalidad y arbitrariedad, v. CRUZ BLANCA M.J., «Individualización judicial y fines de la pena. Discrecionalidad versus Arbitrariedad en la 'fase judicial de concreción de la pena exacta'», MORILLAS CUEVA L., La pena de prisión entre el expansionismo y el reduccionismo punitivo, Madrid, Dykinson, 2016, p. 101 y ss. Sobre la conexión entre proporcionalidad y arbitrio judicial, v. QUINTERO OLIVARES G., «La realidad del principio de proporcionalidad en el Derecho Penal español», AA.VV, Legalidad y defensa. Garantías constitucionales del Derecho y la Justicia Penal, Madrid, Ediciones Jurídicas Castillo de Luna, 2015, pp. 129-178.

$59 \mathrm{Al}$ respecto, basta con pensar a las llamadas circunstancias independientes, caracterizadas por la previsión de un marco edictal de pena establecida sin relación alguna con la pena del delito básico. Así se expresa MELCHIONDA A., «Le circostanze 'indipendenti' sono sempre 'ad effetto speciale'? Una risposta negativa (non 'faziosa', ma 'di parte'), aspettando le Sezioni Unite», www.penalecontemporaneo.it, 3 de abril de 2017, p. 6.

60 En este sentido, v. PULITANÒ D., «Sulla pena», op. cit., p. 659. Según el autor, las circunstancias representan un problema dentro del ordenamiento penal, ya que el enorme poder del juez en la gestión conjunta de los institutos del sistema sancionador contribuye al debilitamiento de la determinación y de la precisión que, en cambio, deberían caracterizar el derecho penal. El autor preferiría eliminar mecanismos de distorsión como las circunstancias, modulando su actuación. 
y a falta de mecanismos de control sobre la actuación judicial, pueden llegar a debilitar la legalidad penal.

Cabe mencionar que, alternativamente a las técnicas de normación ordinarias y varias de la tradición jurídica occidental, una parte de la doctrina se manifiesta en favor de las técnicas de prevención indirecta, para garantizar incluso una mejor actuación del principio de proporcionalidad de la pena ${ }^{61}$. Una política racional que tenga en consideración la prevención de los delitos y la garantía de los derechos fundamentales de la colectividad, acoge con benevolencia una «prevención pre-penal» ${ }^{62}$. Desde esta perspectiva, habría un aumento directo de la libertad del individuo en detrimiento del aumento del quantum punitivo ${ }^{63}$. Dichas técnicas de prevención indirecta permitirían la implementación efectiva de la proporción entre delito y pena, al menos en relación con el aspecto de la necesidad, ya que la pena representaría la extrema ratio ${ }^{64}$ necesitada por el fracaso de una prevención social que, en líneas generales, toma en consideración todos los métodos idóneos, al igual que la sanción, para realizar su finalidad, pero definitivamente menos aflictivos y más cuidadores de las situaciones jurídicas subjetivas del individuo.

Finalmente, a pesar de las dificultades en la realización de un aparato de normas penales que reflejen la proporcionalidad de la pena, es cierto que la actividad legislativa deba tomar en consideración dicho principio ${ }^{65}$, para que el sistema no lleve vicios es-

61 Vid., ex plurimis, CATTANEO M.A., Il liberalismo penale di Montesquieu, Nápoles, Edizioni Scientifiche Italiane, 2000, p. 63. Al respecto, v. también CATTANEO C., «Della pena di morte nella futura legislazione italiana», Politecnico, XLIV, 1860, p. 23. Los autores alaban la obra de sustitución de la intervención sancionadora mediante técnicas de prevención social que puedan evitar la privación de libertad.

62 La expresión es propia de FERRAJOLI L., Il paradigma garantista. Filosofia e critica del diritto penale, Nápoles, Editoriale Scientifica, 2014, p. 237. Según el autor, la verdadera prevención de la delincuencia es anterior a la intervención del derecho penal sancionador, y se manifiesta a través del desarrollo de la formación básica, con la satisfacción de los mínimos vitales, con la construcción del sistema de garantías del que depende la efectividad de la democracia.

63 Se expresa en favor de la progresiva superación del mecanismo de la pena de detención FERRAJOLI L., Diritto e ragione, op. cit., p. 408, promoviendo un radical cambio inicialmente a través de un programa de «minimización» del derecho penal, que requiere sólo la determinación de la pena mínima necesaria por parte del legislador y del juez.

64 Sobre el significado y el valor del principio de subsidiariedad del derecho penal, por el cual éste se debe configurar como extrema ratio del ordenamiento jurídico, v. MANES V., «Principi costituzionali in materia penale», www. cortecostituzionale.it, septiembre de 2013, § 4.1.1. Resulta significativo citar una reflexión doctrinal según la cual la tutela penal como extrema ratio es socavada, hoy más que nunca, por la ausencia o insuficiencia de comunicación entre el sector técnico-científico y los órganos legislativos. En este sentido, v. FIANDACA G., «Legalità penale e democrazia», op. cit., p. 1260. El autor analiza la preocupación de que hay tendencias encaminadas a politizar, a efectos del orden público, la cuestión penal. El énfasis de la tutela de la seguridad pública ha llegado a ser así la presunta ratio democrática de un fuerte endurecimiento del régimen penal, destinado a los nuevos «enemigos» de la sociedad, es decir, los delincuentes reincidentes. Dichas tendencias son el resultado de una pluralidad de factores, entre los cuales constan las graves carencias de know how detectadas en la actividad del legislador. De hecho, hoy en día es fundamental poseer conocimientos extranormativos que permitan a los sistemas político-institucionales producir normas efectivamente capaces de dirigir las conductas contemporáneas. Sobre la dificultad de incorporar los conocimientos científico-tecnológicos citados por parte de la ciencia penal contemporánea internacional, v. amplius FIANDACA G., «Scienze e diritto. Il giudice di fronte alle controversie tecnico-scientifiche. Il diritto e il processo penale», AA.VV., Coord. COSTANTINO S. - RINALDI C., Pensare la complessità. Itinerari interdisciplinari, Palermo, Sigma Edizioni, 2004, p. 175 y ss.

65 Desde la perspectiva de la prevalencia de la finalidad reeducativa de la pena sobre sus demás funciones, v. CADOPPI A. - CANESTRARI S. - MANNA A. - PAPA M., Trattato di diritto penale, op. cit., p. 207. Los autores afirman que la actividad legislativa en la cuantificación abstracta de la pena, respetando el principio de reeducación, debe considerar que haya una proporción entre el desvalor del hecho y la cantidad de sanción, para no perjudicar el conseguimiento de la finalidad reeducativa. 
tructurales que dibujan una insolencia hacia el núcleo de la Constitución ${ }^{66}$. Incluso si las hipótesis de prevención pre-penal fuesen acogidas por parte del ordenamiento jurídico, la pena, con todas las garantías de que goza, seguiría siendo un instrumento necesario e inamovible para huir de la indiferencia frente a los comportamientos criminales, la cual, en la pragmática constante, lleva a un incremento de la tasa de delincuencia ${ }^{67}$ y no favorece el desarrollo de una vida comunitaria pacífica y segura, objetivo último del derecho penal.

\section{LA DETERMINACIÓN JUDICIAL DE LA PENA}

El análisis del principio de proporcionalidad a nivel abstracto ha de ir acompañado de un examen crítico del mismo desde el punto de vista práctico. Como se ha mencionado en las reflexiones efectuadas, no es suficiente evaluar la proporción de una pena frente a un delito sobre la base de inferencias lógicas, lo más objetivas posible, sin tomar en consideración el hecho concreto del cual se genera la sanción.

Siguiendo esta perspectiva, se procederá al examen de la proporcionalidad de la pena en su aspecto concreto, es decir, con respecto a la efectiva determinación de la misma. Ya se ha dicho ampliamente que la determinación de la pena tiene su origen ante todo a nivel normativo y, sólo en un segundo momento, gracias a la actuación del órgano jurisdiccional. Habida cuenta del sometimiento de este segundo paso respecto al primero, no puede descuidarse el análisis de la actividad jurisdiccional para observar cómo, de manera real y funcional, la proporcionalidad entra a formar parte de la pena concretamente impuesta al sujeto delincuente ${ }^{68}$.

Por lo que concierne esta configuración concreta del principio de proporcionalidad de la pena, es oportuno examinar la praxis aplicativa del mismo en ámbito judicial, o sea la norma que, de alguna manera, autoriza la acción de la discrecionalidad de los jueces durante un proceso en que, con las debidas garantías, se aplica el derecho penal sustancial $^{69}$. Con esto se alude, por ejemplo, al art. $72 \mathrm{CP}^{70}$, el cual menciona ímplicitamente la

66 Desde esta perspectiva, se puede observar la amplitud del principio de proporcionalidad, el cual sirve como justificación de todo el derecho penal. Así APPEL I., Verfassung und Strafe, Berlín, Duncker \& Humblot, 1998, p. 171 y ss.

67 La necesaria presencia de la pena en el ordenamiento jurídico es opinión común y pacíica en doctrina. Entre otros, STELLA P., Pena e politica criminale, op. cit., pp. 171-172, incluyendo evaluaciones de carácter ético y moral, señala que el castigo de los criminales de una sociedad, aun sin humiliación, implica que esa sociedad es decente. De hecho, según el autor, lastimar a alguien (en el sentido de que sufra) no significa necesariamente querer o hacer un mal hacia esta persona. Consiguientemente, la pena es la única manera de que la sociedad pueda honrar al delincuente, confiriéndole aquellas atenciones y aquellas curas que él mismo ha ímplicitamente solicitado. La renuncia a la pena puede representar un acto de indiferencia frente a la conducta del delincuente y provoca a menudo un escalation, o por lo menos una continuación, del comportamiento criminal.

68 Hay muchas referencias doctrinales según las cuales no se puede razonar en abstracto acerca de la proporcionalidad, sino que sólo se puede decidir en concreto, dejando a los estudiosos la tarea de estar de acuerdo o discrepar y a los científicos la tarea de dar consejos. Así se expresa LUTHER J., «Ragionevolezza (delle leggi)», Digesto delle discipline pubblicistiche, XII, 1997, p. 342. Sin embargo, como se ha demostrado supra, también a nivel abstracto el principio de proporcionalidad puede ser analizado y encontrar su aplicación ya en la actividad legislativa.

69 Un análisis interesante de la relación entre las funciones de la pena y el proceso penal se encuentra en MARAFIOTI L., «Funzioni della pena e processo penale», AA.VV., Coord. DE FRANCESCO G. - MARZADURI E., Il reato lungo gli impervi sentieri del processo, Turín, Giappichelli, 2016, p. 199 y ss.

70 El art. 72 del Código Penal español establece lo siguiente: « Los jueces o tribunales, en la aplicación de la pena, con arreglo a las normas contenidas en este capítulo, razonarán en la sentencia el grado y extensión concreta de la impuesta». 
tarea de la jurisdicción de elaborar un iter decisorio racional y coherente. El juez, de hecho, tiene que aplicar la pena no sobre la base de una libertad absoluta, sino utilizando los instrumentos de la racionalidad que, aun de manera lacónica, garantizan al ius puniendi una restricción jurídica a tutela del individuo condenado.

Sobre la base de la vigencia del Estado constitucional de Derecho, el poder discrecional del órgano jurisdiccional está vinculado a la aplicación estricta del texto normati$v{ }^{71}$. Sin embargo, la necesaria presencia de límites mínimos y máximos de pena conminable no permite a la actividad jurisdiccional configurar un mecanismo casi automático de mera conexión entre la existencia -a comprobar- de un hecho típico y la imposición oficial y autoritaria de la sanción ${ }^{72}$.

Parece relevante insertar la aplicación concreta del principio de proporcionalidad en la perspectiva de la discrecionalidad judicial, ya que ése tiene su auge, desde el punto de vista práctico, en la configuración de un límite a la arbitrariedad del órgano jurisdiccional. Es justo este límite el que permite, en la esfera propia del derecho penal, la formación de un instrumento como la discrecionalidad, una técnica no ya suelta de cualquier control, sino vinculada jurídicamente a las previsiones legales en materia ${ }^{73}$. A falta de estos vínculos jurídicos, no se podría hablar de discrecionalidad, ya que la aplicación de las normas penales sería inevitablemente arbitraria, lo que representaría sin duda un escenario irrealizable durante la vigencia de un ordenamiento democrático.

Es interesante relevar que, aunque existan unos límites al poder discrecional de los jueces, estos últimos huyen de la ridigez del Estado de Derecho y tienden a favorecer sentencias casi arbitrarias. Se han elaborado, a este respecto, estudios estadísticos que demuestran la existencia de una considerable disparidad de tratamiento hacia un sujeto que ha cometido un tipo de delito, en función del órgano judicial, aun perteneciente al mismo tribunal ${ }^{74}$. Habida cuenta de la necesidad constitucional de una igualdad sustancial, que implica paradójicamente la desigualdad en términos de tratamiento sancionador, es evidente que la excesiva discrepancia entre los hipotéticos juicios de un juez y otro, ante el mismo caso y dadas las mismas circunstancias, representa una amenaza frente a la seguridad jurídica del derecho y de las penas, y también al principio de legalidad y sus corolarios, los cuales legitiman la subsistencia del derecho penal $7^{75}$.

71 La discrecionalidad entendida como mera hermenéutica del texto normativo se denomina discrecionalidad interpretativa. Se diferencia de ésta la discrecionalidad aplicativa, la cual opera gracias al órgano jurisdiccional en la determinación concreta de la pena.

72 Un automatismo de este tipo, encaminado a restringir la actividad judicial a una actuación meramente administrativa, ha de rechazarse. Sin embargo, cabe observar que un exceso de discrecionalidad puede implicar un grave riesgo para la seguridad jurídica. Aun sin violar el principio de legalidad, la progresiva ampliación del poder discrecional de los jueces pone el peligro dicha seguridad.

73 La discrecionalidad del juez se distingue de la arbitrariedad vigente en siglos remotos justo gracias a los vínculos legales. En este sentido, v. DOLCINI E., La commisurazione della pena. La pena detentiva, Padua, Cedam, 1979 , p. 55.

74 Presenta la elaboración de estos estudios CHAZAL J.P., «Le juge et l'élaboration de la sentence», AA.VV., The sentencing. Élaboration de la sentence pénale. Actes du colloque de Bellagio, 1968, p. 80.

75 Para profundizar las disparidades de tratamiento procedentes de la discrecionalidad judicial y los riesgos que esta última conlleva, v. DELOGU T., «Potere discrezionale del giudice e certezza del diritto», Rivista italiana di diritto e procedura penale, 1976, p. 383 y ss. Las investigaciones sociológicas sobre el sentencing de la jurisdicción, aunque se hayan desarrollado en los Estados Unidos, dibujan un cuadro alarmante no sólo para el ordenamiento estadounidense. 


\subsection{La imposición de la pena como límite a la discrecionalidad penal}

La discrecionalidad en la aplicación de la pena encuentra, entre sus límites normativos, las disposiciones de los arts. 61 y ss. del Código Penal español, que perfilan una lista de criterios útiles para determinar la sanción. Es evidente, pues, que el juez está obligado, en el momento en que ejerza su poder discrecional, a tener en debida cuenta la gravedad del delito y la capacidad a delinquir del sujeto agente.

La noción de gravedad del delito, resultante de las circunstancias objetivas del hecho ilícito y del tipo de peligro causado y de la intensidad del dolo o de la negligencia, refleja una dificultad hermenéutica que desemboca en dos corrientes contrarias: por un lado, el énfasis en materia de determinación de la pena debería estar principalmente en la culpabilidad del reo ${ }^{76}$; por el otro, en cambio, la determinación de la sanción habría de referirse tanto a la proporción entre el daño causado y la relación social como al grado de culpabilidad exteriorizado en el hecho típico ${ }^{77}$.

También la capacidad a delinquir da lugar a incertidumbre en el plan aplicativo. No es fácil, pues, velar por que dicho concepto pertenezca al iter decisional sin que haya una aun mínima interferencia de la intuición del juez ${ }^{78}$. Por ejemplo, el órgano jurisdiccional puede encontrarse frente a un caso en que tenga que considerar los motivos que han provocado el agente a cometir el delito, y también el carácter que distingue la personalidad del sujeto. Parece evidente que, en ausencia de una formación específica del juez, la psicología del sujeto se somete a una evaluación como mínimo imprecisa. Con toda probabilidad, de hecho, el carácter del reo se examinará en función de las convicciones personales del juez, aisladas del sistema normativo y de cualquier canon de cientificidad, que garantizaría un análisis más prudente.

Con respecto a la inseguridad que generan los criterios para determinar la pena, cabe mencionar un ejemplo del panorama normativo de otro ordenamiento muy cercano al español, en el que hay una norma específica que vincula al intérprete a interpretar un hecho delictivo con arreglo a criterios hermenéuticos predeterminados. El art. 133 del Código Penal italiano, de hecho, enumera la heterogeneidad de dichos criterios ${ }^{79} \mathrm{y} \sin$ embargo es posible afirmar su potencial carácter omnicomprensivo que aniquilaría tout court la efectividad de la norma ${ }^{80}$.

76 DOLCINI E., La commisurazione della pena, op. cit., p. 52. El autor manifiesta sus preocupaciones acerca del papel de la prevención general en calidad de autónoma finalidad de la pena en el momento de su determinación. En este sentido, expresa su convicción de que la capacidad a delinquir es criterio subjetivo preeminente para orientar la decisión judicial.

77 Esta es la tesis de NUVOLONE P., «Pena (in generale)», Enciclopedia del diritto, vol. XXXII, Milán, Giuffrè, 1982 , p. 804. El autor critica la orientación contraria, propia de Dolcini, afirmando que se equivoca el que hace incapié, en tema de determinación de la pena, principalmente en la culpabilidad.

78 Ibid., p. 806. El juicio sobre la capacidad a delinquir del sujeto agente no se considera el resultado de una rigurosa investigación científica.

79 Para profundizar el tema de la determinación de la pena y las varias interpretaciones, a veces contrarias, que se confieren a los criterios enumerados en el ordenamiento penal italiano, v. DOLCINI E., La commisurazione della pena, op. cit.; MANTOVANI F., Diritto penale. Parte generale, Padua, Cedam, 2015, p. 770 y ss.; SIRACUSANO D., «Problemi attuali della discrezionalità in diritto penale», Indice penale, 1976, p. 437 y ss.; STILE A., «La commisurazione della pena nel contesto attuale del sistema sanzionatorio. Aspetti problematici», AA.VV., Studi in onore di Giuliano Vassalli, vol. I, Milán, Giuffrè, 1991, p. 285 y ss.

80 MILITELLO V., Prevenzione generale e commisurazione della pena, Milán, Giuffrè, 1982, pp. 18-19. El autor menciona el carácter omnicomprensivo del art. 133 Código Penal italiano ya que, dada su amplitud, permite describir exactamente todos los infinitos casos de la vida e identificar, pues, los diversos significados de desvalor 
Desde esta perspectiva, el art. 133 Código Penal italiano se ha definido una fórmula vacía libre de significado jurídico relevante ${ }^{81}$. De hecho, si todos los criterios que el juez podría utilizar se encuentran recogidos en una norma, esta norma es superflua ${ }^{82}$. Los partidarios de esta tesis se quejan de la falta de denuncias de violación de la disposición en cuestión. Se han propuesto interpretaciones que, de alguna manera, valoran el criterio jerárquico: los elementos proporcionados al juez para evaluar la gravedad del hecho y la capacidad a delinquir deberían utilizarse en el orden en que se han enumerado por el legislador. Más allá de las dudas respecto a esta solución, debidas a la necesidad de una visión sistemática y global de los puntos enumerados en el artículo, este tipo de exégesis del texto normativo testifica, como mínimo, la dudosa naturaleza del remedio utilizado por el legislador italiano.

A pesar de las consideraciones efectuadas, para que se determine equitativamente la pena se necesita una evaluación amplia de las circunstancias del delito. A través del examen del cuadro global del hecho típico se puede llegar a una efectiva proporción de la pena conminada al delito cometido. Según esta lógica, parece imprescindible tomar en consideración el razonamiento jurídico puesto en la base de la decisión judicial. Se trata de un iter lógico desarrollado por el órgano jurisdiccional para conseguir el establecimiento de la especie y de la cantidad de pena a imponer.

Sin perjuicio de los esfuerzos efectuados para teorizar la actividad de identificación de la pena, la secuencia lógica en la que se basa el juez adolece de múltiples factores subjetivos que dejan afirmar que dicho iter sea de tipo exclusivamente intuitivo ${ }^{83}$. Si es cierto que, a nivel objetivo, el razonamiento del juez puede resumirse en tres inferencias -inducción, deducción y silogismo práctivo/dispositivo-, cada una de las cuales es lógicamente anterior a las otras ${ }^{84}$, también es cierto que al menos el último paso del razonamiento se ve afectado por las convicciones personales de quien, en aquel caso concreto, debe juzgar.

Las tres inferencias lógicas en que se enmarca el iter decisional con respecto a la aplicación y determinación de la pena pueden resumirse como sigue: (i) una inferencia (tendencialmente) inductiva, encaminada a la conclusión fáctica sobre la verdad histórica del acontecimiento; (ii) una inferencia (tendencialmente) deductiva o calificativa, que

de un hecho y los diferentes tipos criminológicos que pueden realizar en concreto el hecho delictivo. Contra cabe mencionar posiciones por las cuales el artículo citado representa una inútil agrupación de criterios encaminados, en realidad, a desvincular el juez de cualquier límite normativo en favor de su evaluación personal.

81 DOLCINI E., La commisurazione della pena, op. cit., p. 59.

82 Contra, v. por todos CADOPPI A. - CANESTRARI S. - MANNAA. - PAPA M., Trattato di diritto penale, op. cit., p. 195. Los criterios mencionados adquieren, según los autores, una función de garantía esencial al derecho penal. Por tanto, el art. 133 no puede configurarse como una fórmula vacía que deja al juez la facultad de operar según su pensamiento, desvinculándose del texto normativo. Esta opinión testifica, además, la presencia de una doctrina según la cual, aun si los criterios dictados por el legislador representasen la totalidad de los criterios existentes, sería necesaria su transposición en norma jurídica para que los operadores del derecho pudiesen utilizarlos. No se puede, de hecho, castigar sin tener una disposición normativa al respecto, como afirma LONGHI S., Repressione e prevenzione nel diritto penale attuale, Milán, Società Editrice Libraria, 1911, p. 756.

83 DE VERO G., Circostanze del reato e commisurazione della pena, op. cit., p. 136. El escepticismo hacia los esfuerzos de teorización de los criterios para identificar la justa pena impide, según este autor, todo tipo de auténtica normación.

84 CARUSO G., «Commisurazione della pena e discrezionalità del giudice», RONCO M., Persone e sanzioni. Presupposti soggettivi, previsione, comminazione ed esecuzione delle sanzioni penali, Bolonia, Zanichelli, 2006, p. 400. 
permite enmarcar la verdad histórica comprobada en una determinada norma; (iii) un silogismo práctico/dispositivo, que conecta los dos pasos anteriores para irrogar la sanción. Es claro que los dos primeros momentos, inductivo y deductivo, pueden fácilmente alejarse de cualquier realidad subjetiva. La comprobación de la verdad histórica, de hecho, al igual que su vinculación a una eventual norma, es una actividad que deja poco espacio a la intuición y a la manipulación del juez, dada la imposibilidad de ejercer el ius puniendi sin eliminar previamente toda duda razonable acerca de la comisión del delito.

El tercer momento, en cambio, padece naturalmente la interpolación de factores alóctonos respecto al derecho, los cuales impiden la eliminación del momento creativo de connotación del hecho por parte del juez. La actividad jurisdiccional, de hecho, toma en consideración el hecho legalmente identificado para llegar a un determinado éxito sobre la base de un recorrido discrecional inevitablemente impregnado de juicios de valor ${ }^{85}$. Toda discrecionalidad, por cierto, esconde varios perfiles de intuición que no es posible representar normativamente en un esquema objetivo e igualmente aplicable a cada caso concreto. Factores como las propias consideraciones morales, la percepción social de la reinserción del condenado y del efecto disuasorio de la pena, la cultura de la época histórica en que se desarrolla el juicio, velan por que la proporcionalidad de la pena no pueda analizarse con caracteres objetivos suficientemente satisfactorios. A lo mejor éste es el epílogo consiguiente a la imposibilidad de encontrar una conexión natural entre delito y pena $^{86}$. De esta premisa se desprende la imposibilidad de realizar un balance entre la discrecionalidad del juez y la proporcionalidad de la pena, en términos objetivos.

No es casualidad si se ha llegado a teorizar la naturaleza intuitiva de la discrecionalidad en materia penal. Se hace necesaria, pues, una verificación de cada hecho concreto antes de imponer la relativa consecuencia sancionadora. Dejando aparte todo tratamiento sancionador apriorístico ${ }^{87}$, se postula la exigencia de moldear el texto normativo sobre la base de los resultados empíricamente obtenidos. Dentro de la acción permitida por la norma -es decir, dentro del marco edictal establecido por el legislador- el juez goza de una discrecionalidad que permite anular parcialmente la naturaleza proporcional de la relación delito-sanción.

\subsection{El impracticable balance entre proporcionalidad en concreto y discrecionali- dad del juez: posibles soluciones}

El análisis desarrollado hasta ahora implica la calificación del ordenamiento jurídico vigente como sistema normativo en estado de $\operatorname{caos}^{88}$. Esta razón ha fundamentado la necesidad de elaborar nueva doctrina con respecto a la determinación de la pena, poniendo

85 Para FERRAJOLI L., Diritto e ragione, op. cit., p. 401, hay un momento de la actividad jurisdiccional que es la comprensión equitativa del hecho legalmente identificado. Con dicha expresión, el autor se refiere a los casos en que, bajo la misma calificación normativa del hecho, se puedan subsumir diversos y singulares móviles y modalidades de la acción, gravedades del hecho e intensidad de la culpabilidad. Estas características, que diferencian cada hecho de los demás delitos parecidos, forman en su conjunto la connotación del caso a juzgar, cuya identificación y comprensión es tarea del juez al igual que la comprobación de la denotación del hecho delictivo.

86 El problema de cada sistema de determinación de la pena remonta a una cuestión que parece destinada a permanecer sin solución. Al respecto, v. MANNOZZI G., «Razionalità e 'giustizia' nella commisurazione della pena. Il just desert model e la riforma del sentencing nordamericano», Padua, Cedam, 1996, p. 204.

87 Típico ejemplo de un tratamiento sancionador a priori es la vigencia de automatismos sancionadores dentro de un ordenamiento.

88 DOLCINI E., La commisurazione della pena, op. cit., p. 73. 
como objetivo de la investigación una nueva formulación de los criterios interpretativos de los hechos delictivos que puedan adaptarse a las actuales rationes de política criminal. Como ya se ha dicho, es difícil considerar que se pueda llegar a diferenciar satisfactoriamente la aplicación de cada pena, pero esto no obstaculiza la oportunidad de buscar perfiles que sirvan como tendencial solución de la cuestión.

Una de las técnicas que parcialmente ha resuelto el enigma del exceso de discrecionalidad, constitutivo de la consiguiente desproporción entre delito y pena, es la obligación de motivación de las decisiones judiciales ${ }^{89}$. Esta técnica de expresión de las razones que subyacen a la decisión del juez resuelve sólo en parte la antiquísima cuestión de la determinación de la pena proporcionada al hecho delictivo cometido. De hecho, el utilizo de formulaciones estériles y vagas de la motivación no permite gestionar in toto un fenómeno tan amplio como la discrecionalidad del juez. Se ha considerado que la necesidad de vincular una arbietrariedad judicial absoluta fuese expresión de un interés colectivo ya que los órganos jurisdiccionales tienen que rendir cuentas por sus acciones frente a la fuente de la que procede su investidura ${ }^{90}$.

Otra solución imaginable se encuentra en la propuesta, formulada en la época de la Ilustración y del liberalismo penal, de introducir una pública defensa realizada por un magistrado del Ministerio Fiscal ${ }^{11}$. Ya que la cuestión de la determinación proporcionada de la pena afecta a las prerrogativas del imputado o condenado, a lo mejor es oportuno conferir a dicho sujeto un medio para defenderse que esté siempre presente y sea especular al medio utilizado por la acusación. La introducción de tal defensa pondría en la misma posición la acusación y la defensa pública, que procederían del mismo Estado que, si bien considere necesario comprobar la responsabilidad del investigado, percibe la necesidad de garantizar que una eventual imputación pueda contradecirse eficazmente por parte del interesado.

Estas soluciones, por ser parciales, no podrían resolver la antigua cuestión de la discrecionalidad penal en materia de determinación de la pena. El balance entre esta amplia facultad del juez y la referencia constante a los criterios que tienden a una visión proporcional de la sanción es sin duda impracticable al estado actual, ya que factores heterogéneos concurren continuamente en la formación de la convicción del juez. Por esta razón es necesario seguir investigando para encontrar una técnica que pueda colmar las lagunas de un sistema de garantías impregnado de irracionalidades y praxis arbitrarias.

\section{LA POST-DETERMINACIÓN DE LA PENA EN LA FASE DE EJECUCIÓN}

Tras haber analizado el principio de proporcionalidad en los dos momentos de determinación normativa y judicial de la pena, conviene interrogarse sobre la prosecución de la

89 Un excursus sobre la obligación de motivación de las decisiones judiciales, en materia de determinación de la pena, está en CARUSO G., «Commisurazione della pena e discrezionalità del giudice», op. cit., p. 407 y ss.

90 En estos términos se expresa AMODIO E., «Motivazione della sentenza penale», Enciclopedia del diritto, vol. XXVII, Milán, Giuffrè, 1977. El autor describe el alcance de la obligación de motivación como un deber del juez que legitima su actuación.

91 Para profundizar el tema de la defensa pública y su papel de garantía frente al imputado, v. FERRAJOLI L., Il paradigma garantista, op. cit., p. 239 y ss. 
vida de la sanción. El anamnesis efectuado hasta ahora ha permitido evidenciar perfiles de desproporción que hacen vulnerable el ordenamiento vigente. Para obtener un cuadro completo, sin embargo, conviene tener en consideración el tratamiento sancionador en su conjunto. A los dos momentos de determinación de la pena citados consigue, desde luego, la aplicación material de la sanción impuesta. Utilizando una célebre expresión, se puede hablar en esta fase de «post-determinación» de la pena ${ }^{92}$.

Imaginando el análisis desarrollado en un contexto que no sea el mundo jurídico, se puede utilizar el ejemplo del protocolo quirúrgico a seguir para aplicar una determinada terapia. Se trata sólo de una manera ulterior para identificar los varios momentos en que la pena entra en juego en la experiencia humana del reo. Entrando en este escenario, es posible confrontar los elementos que constituyen las diversas fases del tratamiento médico con los del tratamiento sancionador. Ahora bien, se podrían evidenciar los siguientes paralelismos: (a) en primer lugar, el paciente quirúrgico equivale al sujeto autor del delito y la pena a irrogar de alguna manera hace referencia a la cura que el médico debe proporcionar; (b) en segundo lugar, el primer paso relativo al tratamiento sancionador -i.e. la determinación normativa de la pena- puede ser visualizado en este ejemplo como la fase preoperatoria, en la cual se analizan las circunstancias sintomáticas para identificar a nivel teórico una estrategia de cura, al igual que el legislador determina a priori el quantum de pena; (c) la operación quirúrgica, en cambio, representa el justo proceso, a través del cual, como el médico aplica materialmente la cura, así el juez conmina la pena; (d) es evidente que los resultados de la operación serán funcionales a comprender el tipo de convalecencia a los que habrá de someterse el paciente. Este es el momento postoperatorio que, de alguna manera, se compara a la post-determinación de la pena. El magistrado encargado, de hecho, al igual que el médico, tiene en consideración las circunstancias objetivas y subjetivas que varían en función de cada caso concreto. De este modo, durante la ejecución de la pena -y, pues, durante la «convalecencia» del reo- se detectarán modificaciones del tratamiento sancionador que merecen ser analizadas.

El período en que la sanción se aplica materialmente, a través de los métodos propio de cada pena, es el objeto de análisis del presente epígrafe ${ }^{93}$. En primer lugar, conviene subrayar la importancia de este momento dentro del examen del principio de proporcionalidad de la pena. Podría considerarse superflua, prima facie, la referencia de la proporcionalidad penal a una fase meramente ejecutiva. Si la pena ya ha sido determinada normativamente y luego ha sido aplicada por el juez, podría considerarse agotado en esos dos momentos el tema de la proporción. Sin embargo, efectuando un análisis más riguroso, se observa que lo que debe ser proporcionado al delito y a sus circunstancias no es sólo la pena, sino el tratamiento sancionador entero ${ }^{94}$.

La fase de ejecución de la pena-que a menudo se da por sentada y aun así, en realidad, constituye el eje esencial de todo el sistema penal- no es sólo una mera actividad

92 FERRAJOLI L., Diritto e ragione, op. cit., p. 404.

93 Para examinar desde una perspectiva histórica la fase ejecutiva de la pena, v. FRANCHI B., «La dottrina e l'esecuzione delle pene prima e dopo Cesare Lombroso», La Scuola Positiva, 1906.

94 En el análisis del juicio de proporcionalidad efectuado por la Corte Constitucional italiana, MANES V., «Principio di proporzionalità. Scelte sanzionatorie e sindacato di legittimità», Libro dell'anno del Diritto, Roma, Treccani, 2013, § 2, reitera que el principio de proporción se refiere al tratamiento sancionador entero y no sólo a la pena, entendida como institución jurídica abstracta. 
administrativa encaminada a la aplicación tangible de la sanción ${ }^{95}$. Más bien, representa una parte de aquella actividad que, al contrario, es eminentemente jurisdiccional ${ }^{96}$. Clasificar la ejecución de la pena como acción jurisdiccional, en lugar de actividad práctica y administrativa, entraña consecuencias relevantes ${ }^{97}$. La primera de ésas es sin duda la asignación a dicho momento aplicativo de las mismas garantías previstas para todo el mecanismo procesal. Desde esta perspectiva, los preceptos constitucionales en materia penal aseguran que la ejecución de la pena se realice en el respeto, in primis, de la persona y de la dignidad humana, y también de la finalidad que la Constitución otorga a la sanción.

Constatada la relevancia del análisis de la fase ejecutiva en el examen del principio de proporcionalidad, conviene interrogarse sobre la subsistencia de dicho principio en el momento aplicativo de la pena. Primeramente hay que evaluar si se pueda hablar de proporcionalidad de la pena durante la ejecución material de esta última. Se podría afirmar, a este respecto, que la actuación del principio de proporcionalidad termine en el momento en que la sanción es impuesta por el juez con sentencia firme. Esta tesis se basa en que, en efecto, al delito se le atribuye su consecuencia jurídica con la sentencia y, a nivel teórico, la acción del derecho penal se cumple, porque ha alcanzado su objetivo ontológico ${ }^{98}$. Sin embargo, al menos tres argumentos empujan a creer lo contrario, i.e. a opinar que con la irrogación de la pena por parte del juez no cese en modo alguno la acción del principio de proporcionalidad y que este último continúe a desempeñar sus funciones tras la conminación.

En primer lugar, como ya se ha dicho, hay que tener en consideración la naturaleza jurisdiccional de la fase ejecutiva de la pena. De hecho, si se acepta tal conclusión, en detrimiento del carácter meramente administrativo de la ejecución, todos los principios generales deben continuar a operar en aquella actividad que, en realidad, representa sólo una parte del unicum denominado iurisdictio. El principio de proporcionalidad sin duda es parte del conjunto de preceptos constitucionales dictados para dirigir la jurisdicción.

95 Si en el sistema clásico los deberes del juez sólo eran condenar y absolver, hoy sus tareas varían y comprenden el ejercicio de nuevas facultades, como por ejemplo la posibilidad de suspender la pena, imponer medidas de seguridad y curar la reeducación psíquica del condenado. Todos estos aspectos representan sin duda el ejercicio de actividad jurisdiccional y no meramente administrativa, como observa FLORIAN E., «Sulla natura giuridica di talune nuove facoltà del giudice penale», Rivista italiana di diritto e procedura penale, 1910, p. 737.

96 La naturaleza de la fase ejecutiva de la pena es un tema muy discutido en la literatura jurídica. La atribución del carácter jurisdiccional o administrativo a dicha actividad de aplicación material de la pena constituye una discusión acalorada entre la idea clásica según la cual el juez, de alguna manera, sale de escena al final del juicio, y la idea reformadora según la cual se intenta conferir «un caractère juridictionnel prononcé à l'exécution», como afirma CONTI U., «Rapport sur la première question», AA.VV., Actes du Congrès Pénal et Pénitentiaire International de Berlin, Août 1935. Rapports sur les questions du programme de la première section: Législation, vol. II, Berne, Bureau de la Commission Internationale Pénale et Pénitentiaire, 1935, p. 2.

97 Cabe destacar que la mayoría de la doctrina está a favor de atribuir el carácter jurisdiccional a la ejecución de la pena. Para analizar el tema, v. CUELLO CALÓN E., «La intervención del juez en la ejecución de la pena», Anuario de derecho penal y ciencias penales, 1953, pp. 252-264. Sobre la ejecución de la pena, v. también SUBIJANA ZUNZUNEGUI I.J., «El juez en la ejecución de las penas privativas de libertad», Revista electrónica de ciencia penal y criminología, 2005. Con respecto a funciones y finalidades de la ejecución de la pena, v. JUANATEY DORADO C., «Función y fines de la pena. La ejecución de penas privativas de libertad en el caso de los delincuentes de cuello blanco», Revista penal, 2017, pp. 126-145. Sobre la ejecución de la pena en la doctrina internacional, v. TONINI P., Manuale di procedura penale, Milán, Giuffrè, 2017, p. 1021 y ss., y también VIGONI D., «L'esecuzione penale», AA.VV., Procedura penale, Turín, Giappichelli, 2017, p. 899 y ss.

98 Lejos de ser una consideración rigurosa, con «objetivo ontológico» del derecho penal sólo se indica el objetivo primario al que tiende. El derecho penal, de hecho, en su pura esencia, conecta determinados hechos típicos a una consecuencia jurídica denominada sanción. 
En segundo lugar, otra motivación por la cual la proporcionalidad de la pena sería configurable en la fase ejecutiva concierne la finalidad de reinserción social del reo. De hecho, si la irrogación de la pena debe tender a reinsertar al condenado en la sociedad, a través del unicum jurisdiccional caracterizado por la aplicación -en un justo proceso- de la ley con arreglo a la Constitución, es claro que deba continuar a guardarse una proporción entre el hecho cometido y la pena impuesta también durante el período de condena. Es esencial, pues, que el reo continúe a percibir justo, equitativo y entonces proporcionado, el tratamiento sancionador que se le otorgó.

Por último, el ulterior argumento a favor de la tesis expuesta está relacionado con el concepto de discrecionalidad penal, la cual se ha descrito supra como actividad estrictamente vinculada a los preceptos normativos, a fin de evitar que desemboque en la obsoleta arbitrariedad del juez, incontrolable e incostitucional. Si durante la fase ejecutiva el magistrado competente debe de alguna manera garantizar la finalidad reeducativa de la pena -concediendo beneficios, modificando la misma ejecución o estableciendo medidas alternativas- él actuará discrecionalmente. Aplicando los razonamientos ya desarrollados con respecto a la discrecionalidad penal, se puede afirmar que cuando haya discrecionalidad judicial, el escenario debe estar impregnado por el principio de proporcionalidad, so pena de censura por incompatibilidad con la Constitución.

\subsection{La actuación del principio de proporcionalidad en la post-determinación de la pena}

Si se acepta la tesis por la cual la vigencia del principio de proporcionalidad debe perdurar en la fase ejecutiva de la pena, es legítimo dudar de la licitud de las modificaciones sancionadoras introducidas en dicha fase. El fenómeno en cuestión es la esencia de la post-determinación de la pena: se trata de las modificaciones del tratamiento sancionador realizadas tras la resolución definitiva del juez.

Conviene efectuar ante todo una consideración preliminar acerca de la admisión de dichas modificaciones: ¿se pueden considerar legítimas? Se trata de una cuestión ampliamente discutida, que se resuelve comúnmente con una respuesta afirmativa que, por algunos motivos, resulta bastante aproximada. En un cierto sentido, de hecho, puede representar un nonsense la inmutabilidad de la pena en la fase ejecutiva. Al respecto se dice que es inútil continuar a castigar a un sujeto que, con el transcurso del tiempo, ha cambiado, de lo contrario la sanción se convertiría en injusta. Pero un análisis más cuidadosa permite observar que la injusticia de un castigo excesivo no depende del cambio de las características personales del condenado, sino del efecto perverso generado por el quantum desproporcionado de pena establecido en las fases anteriores por el legislador ${ }^{99}$. En cualquier caso, lo que releva a efectos de este análisis es que, al estado actual, la Ley permite a la jurisdicción intervenir para modificar la pena durante su fase ejecutiva.

99 El efecto perverso de la excesiva longitud de las penas es lo que, según FERRAJOLI L., Diritto e ragione, op. cit., p. 404 y ss., podría evitarse a priori para que no se practiquen modificaciones de la pena durante su ejecución. El autor afirma que dicho defecto de la ley penal se debe al perseguimiento de dos finalidades encubiertas, ambas incompatibles con el modelo de las garantías penales. La primera finalidad consiste en la función ejemplar asignada a la pena impuesta, en el sentido de que se asigna a la condena -y no ya a la pena en sí- esta función que asume así un carácter notablemente simbólico. La segunda finalidad es aquella, propia de la ejecución, de la corrección del reo en sentido francamente disciplinar. Esta doble función de la pena (ejemplar en el momento de la condena y disciplinar a la hora de la ejecución), según el autor, confiere a las instituciones un carácter fuertemente totalizador. 
Habida cuenta del posible cambio del tratamiento sancionador en la post-determinación de la pena, es oportuno evaluar su conformidad respecto al principio de proporcionalidad. No toda modificación de la sanción, de hecho, resulta ser obsecuente hacia el principio en análisis. Parece correcto considerar que para evaluar la proporcionalidad de la intervención modificativa se pueden mencionar los «escalones» elaborados por la doctrina alemana. No es suficiente, pues, afirmar que sólo es lícita la modificación que no empeore las condiciones del condenado, es decir, la que cambie la respuesta penal exclusivamente in melius.

Por tanto, hay que comprobar que el tratamiento sancionador renovado supere el control de los requisitos de idoneidad, necesidad y ponderación. Se deberá proceder, pues, a un análisis de la situación anterior al cambio y entender las razones por que se hace necesario mutar la sanción. En un momento posterior, una vez que se hayan elaborado las nuevas condiciones de pena, el hecho cometido y las circunstancias subsistentes en aquel momento de la fase ejecutiva se evaluarán con arreglo a los tres criterios indicados. Sólo de este modo podrá considerarse respetado el principio de proporcionalidad en las modificaciones introducidas durante la ejecución de la pena.

\subsection{La restorative justice en el futuro de la punibilidad: reparación proporcionada} del daño

Una prueba ulterior de la importancia del análisis de la proporcionalidad en la fase de ejecución de la pena se adquiere mediante la idea de justicia restaurativa en la que se enmarca el denominado delito reparado. La justicia restaurativa o reparadora, llamada también restorative justice, parte del supuesto de que se deba considerar el delito en términos de daño a las personas ${ }^{100}$. Sobre la base de esta afirmación, la filosofía en análisis tiende a evitar la aplicación de la pena fuera de los casos en que sea estrictamente necesaria, es decir, cuando el reo no pueda o no quiera reparar el daño causado. El perfil del delito reparado no estaría relacionado de por sí con las cuestiones relativas a la post-determinación de la pena, ya que constituye un autónomo delito con el propio marco edictal. Sin embargo, sobre la base de las objeciones a tal impostación dogmática, se puede distinguir la idea original del delito reparado de la reparación que se lleva a cabo mediante un post factum posterior a la condena. La realización de un hecho subsiguiente a la conducta delictiva para que se corrija el daño causado está, pues, vinculada al tema de la proporcionalidad de la pena en su fase ejecutiva. Hay que interrogarse sobre si un eventual post factum pueda justificar no sólo la inaplicación, sino la total extinción de la sanción conminada en función del hecho de que el daño ha sido reparado por el sujeto agente. Parece correcto aplicar la misma solución analizada hace un momento con respecto a las modificaciones

100 Sobre la idea de justicia restaurativa, pionero en Italia resulta el estudio de MANNOZZI G., La giustizia senza spada. Uno studio comparato su giustizia riparativa e mediazione penale, Milán, Giuffrè, 2003, p. 43 y ss. La autora analiza el origen extranjero del concepto reparador y proporciona un análisis detallado del problema. Al respecto, v. MANNOZZI G. - LODIGIANI G.A., La giustizia riparativa. Formanti, parole e metodi, Turín, Giappichelli, 2017, y también DE FRANCESCO G., Punibilità, Turín, Giappichelli, 2016, p. 90 y ss. En la doctrina española, sobre la justicia restaurativa, v. CARNEVALI RODRÍGUEZ, R., «La justicia restaurativa como mecanismo de solución de conflictos. Su examen desde el derecho penal», Justicia Juris, 2017, pp. 122-132. Vid. también JIMÉNEZ BOLAÑOS J., «Breve análisis de la justicia restaurativa», Revista de Ciencias Jurídicas, 2015, pp. 161-174, y DOMINGO DE LA FUENTE V., «¿Qué es la Justicia Restaurativa?», Criminología y Justicia, 2012, pp. 6-11. 
del tratamiento sancionador. Es decir, conviene efectuar el habitual examen de los tres niveles, porque básicamente la premisa inicial es la misma en ambos los casos: aquí también tiene lugar una mutación de las condiciones sancionadoras. La diferencia, sin embargo, está en las consecuencias de la modificación: por un lado se sustituye una pena con otras medidas sancionadoras, aun alternativas; por otro, en cambio, la pena se extingue.

Debido al efecto tan relevante de la justicia restaurativa, el examen de proporcionalidad ha de efectuarse con particular rigor y ha de involucrar también un elemento que hasta ahora no ha comparecido: la reparación del daño. El juicio de proporcionalidad en su estructura originaria, de hecho, se perfila como una contraposición bicéfala entre delito y pena. Imaginando, al contrario, un sistema de justicia restaurativa vigente, la comprobación de la subsistencia de proporcionalidad se centraría en un trinomio constituido por los tres siguientes elementos: delito-daño, pena, reparación del daño. 